\title{
Manipulation of free volumes in a metallic glass through Xe-ion irradiation
}

X.L. Bian ${ }^{1}$, G. Wang ${ }^{1}$, H.C. Chen ${ }^{2}$, L. Yan ${ }^{2}$, J.G. Wang ${ }^{1}$, Q. Wang ${ }^{1}$, P.F. Hu ${ }^{1}$, J.L. Ren ${ }^{3}$, K.C. Chan ${ }^{4}$, N. Zheng ${ }^{5}$,

A. Teresiak ${ }^{5}$, Y.L. Gao ${ }^{1}$, Q.J. Zhai ${ }^{1}$, J. Eckert ${ }^{6,7}$, J. Beadsworth ${ }^{8}$, K.A. Dahmen ${ }^{8}$, and P.K. Liaw ${ }^{9}$

${ }^{1}$ Laboratory for Microstructures, Institute of Materials, Shanghai University, Shanghai 200444, China

${ }^{2}$ Key Laboratory of Nuclear Radiation and Nuclear Energy Technology, Chinese Academy of Sciences, Shanghai 201800, China

${ }^{3}$ School of Mathematics and Statistics, Zhengzhou University, Zhengzhou 450001, China

${ }^{4}$ Department of Industrial and System Engineering, The Hongkong Polytechnic University, Hongkong, China

${ }^{5}$ IFW-dresden, Institute for Complex Materials, P.O. Box 270116, 01067 Dresden, Germany

${ }^{6}$ Erich Schmid Institute of Materials Science, Austrian Academy of Sciences, Jahnstraße 12, A-8700 Leoben, Austria

${ }^{7}$ Department Materials Physics, Montanuniversität Leoben, Jahnstraße 12, A-8700 Leoben, Austria

${ }^{8}$ Department of Physics, University of Illinois at Urbana Champaign, 1110 West Green Street, Urbana IL 61801, USA

${ }^{9}$ Department of Materials Science and Engineering, The University of Tennessee, Knoxville, TN 37996, USA Email: g.wang@ @ shu.edu.cn

\begin{abstract}
The origin of the deformation in metallic glasses is attributed to rearrangements of atoms in some structurally weak spots behaving as flow units, which are associated with free volumes. In the present study, Xe-ion beam is used to manipulate the free-volume fraction, and influence on the mechanical behavior of a Zr-based metallic glass. The irradiation at low dosages can change the structure by increasing the free volume, and by homogenising the distribution of free volume. The increase in the free-volume fraction is equivalent to the increase in the deformation temperature, thus resulting in the decrease in the yield strength. The analysis of stochastic strain burst size in the metallic glass irradiated at different dosages indicates that the strain burst depends on the yield strength and homogeneity of the glassy phase. The results of this study highlight the fact that the quantitative manipulation of the homogeneity and the amount of free volumes can be achieved through low-dose ion irradiation, which can modify the mechanical behavior of metallic glasses.
\end{abstract}

Keywords: Metallic glasses; irradiation; free volume manipulation; micro-pillar compression; in-situ tension 


\section{Introduction}

Metallic glasses are a type of disordered materials prepared by rapid quenching of supercooled liquids, and inevitably inherit intrinsic structural heterogeneities as well as a large number of extrinsic casting defects [1-12]. These heterogeneities lead to the formation of weak spots enveloped by elastic surroundings, that are known as free volumes [1,6] or liquid-like zones $[3,5]$. These free volumes are believed to be associated with plastic flow, which likely plays a crucial role in understanding the nature of metallic glasses [3-8]. Extensive research efforts have been devoted to elucidate the relationship between the heterogeneity and the dynamic behavior $[13,14]$, relaxation $[3,6,8]$, and atomic rearrangement $[3,4,9,10]$. Upon shear loading, these heterogeneous regions are easily aggregated to form weak spots, resulting in inhomogeneous deformation and catastrophic damage [15]. Furthermore, these heterogeneities result in deterioration of the properties of metallic glasses, such as degradation of the wear properties [16,17], corrosion resistance [18-22], and fatigue behavior $[11,12]$. Therefore, a reduction of the heterogeneous structure in metallic glasses is of crucial importance in attaining excellent mechanical properties.

Surface treatments, such as the shot peening [23] and laser pulse processing [24,25] of metallic glasses demonstrate that the structural changes on the surface could result in residual stresses on the surface, which could further modify the plastic-deformation ability of metallic glasses $[23,24]$. Ion irradiation, an alternative method, can also induce structural modification of the surface of metallic glasses [26-37]. When metallic glasses are ion-irradiated, the most dominant mechanism involves the inelastic collisions between high-energy ions and solids that can generate certain activated units, such as structural defects and nano-crystallization [27-35]. Nevertheless, the particular influence of ion irradiation on the mechanical behavior of metallic glasses is now somewhat controversial. Some studies found that a high-irradiation dosage could enhance the surface properties, and then improve the plastic-deformation ability with increasing irradiation dosages [26,27,35-40]. However, results of other investigations revealed that ion irradiation could reduce surface smoothness, with the loss of fracture toughness [41]. More recently, a low-dosage irradiation was found to induce the precipitation and coarsening of nano-precipitates, which resulted in a change in the hardness of ferrite steels [42]. Motivated by the previous research, we proposed to manipulate the amount of 
free volumes in the glassy phase through an ion beam, which resulted in the change in the mechanical behavior of metallic glasses.

Accordingly, a low-dosage Xe-ion irradiation experiment was conducted to modify the surface structure of a $\mathrm{Zr}_{50.7} \mathrm{Cu}_{28} \mathrm{Ni}_{9} \mathrm{Al}_{12.3}$ (atomic percentage, at.\%) metallic glass. Compression, tension, and nanoindentation experiments were then performed to characterize the mechanical behavior, which was further related to the structural evolution during irradiation. According to the model of free volume $[6,43]$, a quantitative correlation between the free-volume-evolution time and the yield strength of metallic glasses was constructed to further elucidate the influence of irradiation. The effects of irradiation on plastic flow of metallic glasses were examined in light of the intermittent shear-avalanche critical behavior. Thus, this study provides a new perspective to the understanding of free volume in metallic glasses, which leads to significant changes in their mechanical properties.

\section{П. Experimental procedure}

The $\mathrm{Zr}_{50.7} \mathrm{Cu}_{28} \mathrm{Ni}_{9} \mathrm{Al}_{12.3}$ metallic glass was selected for the present study. Ingots of the Zr-based metallic glass were prepared by arc-melting a mixture of pure metal elements with a purity greater than $99.99 \%$ (weight percentage, wt.\%) in a titanium-gettered high-purity argon atmosphere, followed by suction casting in a $\mathrm{Cu}$ mold to form the rod-like metallic glass. The sheet specimen, with a diameter of $3 \mathrm{~mm}$ and a thickness of $2 \mathrm{~mm}$, was cut from the rod-like samples using a diamond saw with water cooling, two parallel ends were ground to within $10 \mu \mathrm{m}$, and one end mechanically polished to a mirror finish. The structure of the glassy phase of the as-cast metallic glass was ascertained by the X-ray diffraction (XRD) using a Rigaku D \max-2550 diffractometer with $\mathrm{Cu}-\mathrm{K} \alpha$ radiation generated at $40 \mathrm{kV}$. Micro-pillars were fabricated from the irradiated and non-irradiated samples by the focused ion beam (FIB) in a FEI-600i FIB/scanning electron microscope (FIB/SEM) dual-beam system. The milling process of the micro-pillars is summarized in Supplementary Fig. S1.

A terminal of a $320 \mathrm{kV}$ high-voltage experimental platform, equipped with an electron-cyclotron resonance ion source at the Institute of Modern Physics, Lanzhou, China, providing a 7-MeV $\mathrm{Xe}^{26+}$ beam for irradiation, was used. The resulting damage profiles, including 
simulated trajectories and the depth perpendicular to the incident ions in the metallic glass, are shown in the Supplementary Fig. S2. The simulation results demonstrate that the penetration depth of around $2 \mu \mathrm{m}$ can be achieved in this study. The total incident flux was approximately $3.29 \times 10^{14}$ ions $\mathrm{cm}^{-2}$, corresponding to approximately $1 \mathrm{dpa}(\mathrm{dpa}$, as a unit of the irradiation damage, stands for the displacement per atom, defined as the average number of displacements per atom, per unit volume, and per unit time for a given irradiation dosage). Four Zr-based metallic glass samples with mirror ends were subjected to irradiation treatments at different dosages $(0,0.5,1$, and 5 dpa) at room temperature and base pressure below $5 \times 10^{-5} \mathrm{~Pa}$.

The microstructures of the four samples were investigated by the micro-area XRD using a Siemens Micro-diffractometer, with the $\mathrm{Cu}-\mathrm{K} \alpha$ radiation operating at $40 \mathrm{keV}$. The wavelength of the incident beam was $0.15418 \mathrm{~nm}$. The size of the diffraction area on the metallic glass surface was 1 $\mathrm{mm}$ in diameter, and each sample was examined three times in the different areas. High resolution transmission electron microscopy (HRTEM) observations were performed using a JEM-2010F microscope operating at $200 \mathrm{kV}$. Electron-transparent foils for HRTEM were extracted from the irradiated surface of the metallic glass by FIB in a FEI-600i FIB/SEM dual-beam system. For comparison, the HRTEM observation areas of the metallic glass irradiated at different dosages were selected at the same irradiation depth (approximately $1 \mu \mathrm{m}$ ) (Supplementary Fig. S3). To further obtain the structural information, the selected area electron diffraction (SAED) pattern was recorded, and the fast Fourier transformation (FFT) pattern was deduced from the HRTEM images by using Gatan Digital Micrographs software. The SAED pattern can provide a micro-correspondence between the morphology observation and diffraction message. The FFT pattern can provide the diffraction information of the glassy phase in a very small region (on a nano-scale).

Instrumented nanoindentation experiments were performed using a MTS nanointender XP (Oak Ridge, TN) with a Berkovich-diamond tip. The tip diameter of the Berkovich indenter used in the present study was $50 \mathrm{~nm}$ that is significantly less than the tip diameter (approximately $650 \mathrm{~nm}$ ) of the spherical indenter [44]. Sharper indenter (the Berkovich indenter) can initiate more shear bands compared to the blunter indenter (the spherical indenter). Fused silica was used as a standard sample for the initial calibration. Noteworthy, one penetration test must be finished in 300 
$\mathrm{s}$ to exclude the thermal-drift influence on the mechanical properties of metallic glasses. The maximum load was supposed to be $180 \mathrm{mN}$ at a loading rate of $0.6 \mathrm{mN} \mathrm{s}^{-1}$, and then indentations were conducted under a load-control mode of $180 \mathrm{mN}$ at different loading rates of 1, 2, and $3 \mathrm{mN}$ $\mathrm{s}^{-1}$. For each loading rate, ten nanoindentation experiments were performed. The peak load was held constant for $5 \mathrm{~s}$ to negate the influences of the creep on the hardness and elastic modulus. To explore the background noise from the vibration, and the thermal drifting of the nanoindentation instrument, the $10 \%$ peak load was held constant in the unloading segment, which is summarized in the Supplementary Fig. S4. A set of pillars with uppermost diameters of $\sim 650 \mathrm{~nm}$ and aspect ratios of around 2 with a $6^{\circ}$ taper angle was successfully fabricated through step-by-step decreasing of the FIB current at different milling stages [see Supplementary Fig. S1]. Micro-pillar compression experiments were performed using a modified nanoindentation system (Minneapolis, MN) with a diamond flat-end indenter of $10 \mu \mathrm{m}$ in diameter. All the micro-pillars were compressed under a displacement-control mode at a strain rate of $4 \times 10^{-3} \mathrm{~s}^{-1}$. The samples for the in-situ tension tests were also prepared using a FEI-600i FIB/SEM dual-beam system. The in-situ tension tests were performed using a JEM-2010F microscope operating at $200 \mathrm{kV}$ equipped with a Gatan Model 654 single-tilt straining holder. The tension velocity was $0.1 \mu \mathrm{m} \mathrm{s}^{-1}$. The effect of electron beam on the tension ductility is documented in the Supplementary Materials, which can be excluded.

\section{Results}

The micro-area XRD patterns show that all irradiated metallic glasses are completely glassy, with an apparently diffuse peak [Fig. 1(a)]. The differences between these micro-area XRD patterns, i.e., $3\left(I_{0.5}-I_{0}\right), 3\left(I_{1}-I_{0}\right)$, and $3\left(I_{5}-I_{0}\right)$, are also plotted in Fig. 1(a), which indicates obvious occurrence of the structural evolution due to irradiation. After fitting the diffuse peaks of the micro-area XRD patterns using a pseudo-Voigt function [Fig. 1(b)], the position and the full width at half maximum (FWHM) of the peak are obtained, which are used to characterize the structural evolution of the glassy phase, and plotted as functions of the irradiation dosage [Fig. 1(c)]. Evidently, the value of the FWHM increases with increasing dosage from 0 to $1 \mathrm{dpa}$, and then slightly decreases at $5 \mathrm{dpa}$. The peak position shifts to a lower angle with an increase in the dosage, 
indicating that the average inter-atomic distance of the glassy phase becomes larger [45], i.e., a

dilatation occurs.

Furthermore, the transmission electron microscopy (TEM) results provide substantial images describing the structural evolution induced by the irradiation [Fig. 2]. For the as-cast sample, the bright-field image [Fig. 2(a)] shows a homogenous contrast without any dark spots corresponding to crystalline phases. The high-resolution image [Fig. 2(b)] exhibits a mazy and homogeneous pattern, which is typical of a monolithic glassy phase. The inset of Fig. 2(a) shows a SAED pattern with two diffraction halos. An FFT pattern [Fig. 2(c)] corresponding to the region covered by a white rectangle in Fig. 2(b) does not show any diffraction spots for crystalline phases. All these features indicate an inherent glassy character of the metallic glass. At a dosage of $0.5 \mathrm{dpa}$, the bright-field image and the SAED pattern do not show any changes compared to that in the as-cast sample [Fig. 2(d)]. The high-resolution image of one blurred dark spot does not show a significant lattice-fringe pattern, indicating a fully-glassy structure [Fig. 2(e)]. The FFT image further confirms the glassy nature [Fig. 2(f)]. For the metallic glass irradiated at $1 \mathrm{dpa}$, the bright-field image shows some tiny dark spots [Fig. 2(g)]. Although the SAED pattern [the inset of Fig. 2(g)] and the high-resolution image [Fig. 2(h)] also exhibit a fully-glassy structure, the FFT image shows some faint diffraction spots, indicating a disorder-order transformation [Fig. 2(i)]. At a dosage of $5 \mathrm{dpa}$, the bright-field image [Fig. 2(j)] shows the appearance of many dark spots, although the SAED pattern [the inset of Fig. 2(j)] also suggests the glassy feature. The high-resolution image clearly shows some lattice-fringe patterns, indicating nano-crystallization [Fig. 2(k)]. The nano-crystals exhibit an average size of $6 \mathrm{~nm}$, embedded into the glassy phase matrix [Figs. 2(j) and (k)]. The FFT images in Fig. 2(l) show some diffraction spots, confirming the crystalline-phase precipitation. These nano-crystals contribute to the sharpening of the diffuse peak [Fig. 1(a)], which results in the decrease in the FWHM of the diffraction peak in the micro-area XRD [Fig. 1(c)]. Furthermore, through the measurement of the profile of the diffraction halos (Fig. S5), the radius of the diffraction halo, $r$, as a function of the dosage is plotted (Fig. S6). Obviously, with an increase in the irradiation dosage, the radius of the diffraction halo decreases, indicating an expansion of the inter-atomic distance of the glass. Thus, the TEM results further confirm that the dilatation of the glassy phase occurs due to the irradiation. 
Based on the diffuse peak shift, the volume dilatation could be quantitatively estimated. The scattering vector, $Q=4 \pi \sin \theta / \lambda$, where $\theta$ is half of the scattering angle, and $\lambda$ is the wavelength of the X-ray beam $(\lambda=1.5418 \AA)$, is used to quantify the volume changes according to

$$
\frac{V_{\varphi}}{V_{0}}=\left(\frac{Q_{0}}{Q_{\varphi}}\right)^{3},
$$

where $V_{\varphi} / V_{0}$ is the reduced mean atomic volume at the dosage of $\varphi$, with the reference dosage of 0 dpa [46]. The excess volume due to the $0.5 \mathrm{dpa}$ irradiation can be determined to be $V_{0.5} / V_{0}=1.0079$. In general, the free-volume fraction in rapidly-quenched metallic glasses is approximately $1 \%$ [1]. The volume dilatation $(\sim 0.79 \%)$ due to irradiation can be treated as a complete increase in the free-volume fraction because the changes in the volume resulting from the phase transformation, such as crystallization, can be excluded at $0.5 \mathrm{dpa}$. Therefore, the irradiation at $0.5 \mathrm{dpa}$ leads to an increase in the free-volume fraction of the sample by approximately $0.79 \%$ [46]. The increase in the free-volume fraction indicates that the atoms in the irradiated glassy phase are packed more loosely than that in the non-irradiated case. This trend contributes to broadening of the diffraction peak because the loose packing causes the atomic configuration to be more prone to disorder. Moreover, the values of $V_{1} / V_{0}$ and $V_{5} / V_{0}$ are calculated to be 1.0081 and 1.0087 , respectively. For the metallic glass irradiated at $1 \mathrm{dpa}$, the nano-crystals are very small in size and the volume fraction, in particular, the diffraction peak width at 1 dpa still increases, based on which it can be inferred that the disorder of the glassy phase is still enhanced at $1 \mathrm{dpa}$. Thus, the increment of free volumes $(0.81 \%)$ at $1 \mathrm{dpa}$, regardless of the small nano-crystals precipitation, is believed to be valid. The irradiation at $5 \mathrm{dpa}$ results in the precipitation of numerous large nano-crystals, which has significantly caused width shrinkage in the diffraction peaks. Therefore, the calculation of the increment of free volumes when the samples are irradiated at $5 \mathrm{dpa}$ is not reliable. Furthermore, the irradiation at 0.5 and $1 \mathrm{dpa}$ leads to a significant increase in the excess free-volume fraction by 0.79 and $0.81 \%$, respectively, compared to the case without irradiation. This quantity of the increment of free volumes is consistent with the free-volume creation during plastic deformation of metallic glasses known to occur in shear bands $[47,48]$.

The irradiation can only influence the surface of materials. Therefore, all the mechanical tests have to be performed on the surface. Compression tests of micro-pillars are carried out to find the 
yield strength of the irradiated metallic glass. To assure the repeatability of the test results, the

micro-pillar compression test for each irradiated metallic glass is repeated four times. The SEM images of the as-fabricated micro-pillars of the metallic glass are shown in Fig. 3(a). The compressed micro-pillars are shown in Fig. 3(b) for comparison. The representative stress-strain curves are plotted in Fig. 3(c), exhibiting an initial elastic deformation, followed by the jerky-flow behavior manifested by several load drops [49]. The jerky flows are attributed to shear banding [15]. The yield points in the stress-strain behaviors are marked by arrows in Fig. 3(c). The determination of the yield strength of the metallic glass is representatively shown in Fig. 3(d). The elastic-deformation stage in the stress-strain curve of the metallic glass can be linearly fitted by a red dash line. When the stress is increased to be higher than $2.31 \mathrm{GPa}$, the stress-strain curve exhibits a stress step, i.e., a pop-in event, indicating an occurrence of plastically shearing [the inset of Fig. 3(d)]. Therefore, the stress of $2.31 \mathrm{GPa}$ is believed to be the yield strength of the metallic glass without the irradiation. The values of average yield strength are listed in Table I. For the as-cast micro-pillar, the yield strength is up to $2.23 \mathrm{GPa}$, which is significantly higher than that of the bulk sample ( 1.90 GPa) [50]; however, comparable to the value reported in the literature [51]. Irradiation at $0.5 \mathrm{dpa}$ results in the decrease in the yield strength by $\sim 21 \%$ (1.77 GPa). Further increasing the dosage to 1 and 5 dpa leads to a slight increase in the yield strengths to 1.88 and 1.84 GPa, respectively.

Further characterization of the plastic deformation is performed by in-situ TEM tension tests. Figure 4 shows the sequences of TEM images presenting different stretching stages of the irradiated metallic glass. The thickness of all the samples is 70-72 nm (Fig. S7), and the determination of the elongation is also documented (Fig. S8). All the four samples exhibit a necking behavior. At the final fracture stage, shear localization occurs in the necking part. The elongations, $\delta_{\mathrm{N}}$, of four samples before necking are marked in Fig. 4 , and the $\delta_{\mathrm{N} 0.5}$ value at 0.5 dpa approaches $23 \%$. Further increase in the stress leads to gradual enlargement and spreading out of the necked region, resulting in the maximum elongation, $\delta_{\max 0.5}$, of $56 \%$ for the metallic glass irradiated at $0.5 \mathrm{dpa}$. Compared to the values of $\delta_{\mathrm{N} 0}=14 \%$, and $\delta_{\max 0}=27 \%$ (very close to the plastic strain of $25 \%$ for Ref. 51 ) of the non-irradiated metallic glass, the 0.5 dpa irradiation significantly improves the ductility of the 
metallic glass. At 1 and $5 \mathrm{dpa}$, the maximum elongations of the metallic glass approach, $\delta_{\max 1}=34 \%$ and $\delta_{\max 5}=36 \%$, respectively, which are less than the values at $0.5 \mathrm{dpa}$.

The mechanical behavior of the metallic glass in a localized region can be characterized by the micro-pillar compression and in-situ TEM tension tests. Therefore, forty indentation experiments were further performed for each sample to characterize the distribution of the mechanical behavior. Representative load-displacement $(P-h)$ curves at different dosages and a loading rate of $1 \mathrm{mN} \mathrm{s}^{-1}$ are shown in Fig. 5(a). The enlarged curves in the loading stage show some undulations corresponding to the pop-in events [Fig. 5(b)]. Figure 5(c) shows the curves at different loading rates and a dosage of $0.5 \mathrm{dpa}$. The pop-in events can also be observed in the loading stage [Fig. 5(d)]. The $P$ - $h$ curves of the metallic glass irradiated at 0,1 , and $5 \mathrm{dpa}$, and at different loading rates are also plotted (Fig. S9).

In general, nanoindentation is performed in a small nanometer-size volume, which reflects the properties in a very small localized region [52]. Thus, the scattered hardness values measured from the nanoindentation technique correspond to the inhomogeneity of the metallic glass, which has been confirmed by the analysis of the origin of the first shear band during the nanoindentation tests [44]. Figure 5(e) plots the scattering of the forty hardness values of the metallic glasses irradiated at four dosages. For the as-cast one, the hardness exhibits the largest range from 5.59 to 6.77 GPa, with the largest variation of $9 \%$ about its average value of $6.39 \mathrm{GPa}$. After being irradiated at $0.5 \mathrm{dpa}$, the hardness of the metallic glass is confined within a very narrow range, from 5.95 to $6.44 \mathrm{GPa}$, indicating the smallest variation of $4 \%$ about its average value of $6.23 \mathrm{GPa}$. At $1 \mathrm{dpa}$, the scatter range of hardness is enlarged slightly, from 5.96 to $6.49 \mathrm{GPa}$, with an average value of $6.12 \mathrm{GPa}$ and a variation of $5 \%$. With an increase in the dosage to $5 \mathrm{dpa}$, the hardness variation ranges from 5.62 to $6.65 \mathrm{GPa}$, with an average value of $6.22 \mathrm{GPa}$ and a variation of $8 \%$. The average hardness value generally decreases monotonically with increasing the dosage from 0 to $1 \mathrm{dpa}$ because the free-volume fraction increases. Further increasing the dosage to 5 dpa leads to a slight increase in the hardness, attributed to the precipitation of the nanoparticles, which can act as an enhanced phase to prohibit the formation and propagation of the shear bands [36].

Regarding the scattering hardness value [Fig. 5(e)], Weibull statistical analysis is introduced to further characterize the changes of the mechanical properties [53]. The detail of the calculation of 
the Weibull modulus is provided in the Supplementary Materials. Figure 5(f) shows the Weibull plots of the hardness values at different dosages, revealing that the Weibull modulus, $m$, increases with the increase in the irradiation dosage from 0 to $1 \mathrm{dpa}$. At an irradiation dosage of $5 \mathrm{dpa}$, the Weibull modulus decreases dramatically. The maximum Weibull modulus approaches 86.0 at 0.5 dpa. The Weibull modulus reflects the degree of scattering in the hardness value. A higher $m$ value usually represents narrower scattering and a higher reliability [54], and also indicates that the material is more homogeneous. Notably, although the nanoindentation depth in the present study is greater than $10 \%$ of the irradiation depth $(2 \mu \mathrm{m})$, the elastic recovery of the substrate does not significantly influence the mechanical properties of the irradiated surface layer, as shown in Fig. S10.

\section{Discussion}

According to the literature, radiation-induced viscous flow can occur [26], which can significantly change the properties of the materials. According to the Stokes-Einstein relationship, the viscosity of the glassy layer irradiated by heavy ions can be expressed as follows:

$$
\frac{\eta}{t}=\frac{k T}{6 \pi r D \Phi F_{D}}
$$

where $\eta$ is the viscosity of the metallic glass during irradiation, $\Phi$ is the ion fluence, $D$ is the normalized diffusion constant, $t$ is the relaxation time, $T$ is the temperature, $k$ is the Boltzmann constant $\left(1.381 \times 10^{-23} \mathrm{~J} \mathrm{~K}^{-1}\right), r$ is the atomic radius, and $F_{D}$ is the damage-energy deposition per unit length [26]. The normalized diffusion constant, $D$, is approximately $25 \AA^{5} \mathrm{eV}^{-1}$ [26], the damage-energy deposition per unit length, $F_{D}$, is $160 \mathrm{eV} \AA^{-1}$ [55], and the atomic radius, $r$, is approximately $2 \AA$ in Zr-based metallic glasses [45]. The dosage of 0.5 dpa corresponds to the ion fluence, $\Phi$, of $1.65 \times 10^{14}$ ions $\mathrm{cm}^{-2}$. Since the viscous flow can occur due to the irradiation, the local temperature of the metallic glass can approach the melting temperature. Thus, the temperature is selected as $1500 \mathrm{~K}$ [26]. Based on the above mentioned values, the value of $\eta / t$ is calculated to be 8.3 $\times 10^{6} \mathrm{~N} \mathrm{~m}^{-2}$. The critical value of $\eta / t$ for a viscous flow was estimated to be approximately $4.0 \times 10^{8}$ $\mathrm{N} \mathrm{m}^{-2}$ [26]. The calculated viscosity $\left(8.3 \times 10^{6} \mathrm{~N} \mathrm{~m}^{-2}\right)$ at $0.5 \mathrm{dpa}$ is 48 times less than the critical value $\left(4.0 \times 10^{8} \mathrm{~N} \mathrm{~m}^{-2}\right)$. However, this discrepancy in the values can be compensated by the diffusion 
enhanced through the thermal spike and ballistic mixing [26]. Violent

nucleus-nucleus collisions can create displacement cascades and thermal spikes. The center of the cascade forms vacancy-rich regions and absorbs abundant energy to cause melting and resolidification $[30,33,56]$. Therefore, the viscous flow can occur on the surface of the metallic glass irradiated at $0.5 \mathrm{dpa}$, and the cascade center generates large amount of defects, such as free volumes. Moreover, accompanying the viscous flow, collective atoms participate in the shift and rearrangement, bringing out the uniformity of the glassy phase. Thus, the Weibull modulus at the dosage of $0.5 \mathrm{dpa}$ is higher than that of the as-cast sample. At a dosage of $1 \mathrm{dpa}$, although the viscous flow on the surface is enhanced by the irradiation, the thermal effect of the Xe-ion irradiation seems to be improved significantly. This thermal effect causes the homogeneous structure to be broken because of the occurrence of the disorder-order transformation [Figs. 2(h) and (i)]. Some small nano-crystals appear on the glassy phase, which would interact with the shear-band formation and propagation under the nanoindenter. Since the volume fraction of these nano-crystals is very small, not all nanoindenting can encounter the nano-crystals. Therefore, the homogenisation due to the irradiation is slightly deteriorated. Thus, the Weibull modulus at 1 dpa is slightly lower than that at $0.5 \mathrm{dpa}$. When the irradiation dosage is increased to 5 dpa, a highly-heterogeneous microstructure, i.e., numerous nano-crystalline phases are formed, ultimately resulting in the further decrease in the Weibull modulus.

The XRD results already indicate that the free volume increases by approximately $0.79 \%$ at 0.5 dpa. According to the free-volume model, the shear flow is dominated by a competition between the increase rate of the average free volume per atom, $v_{f}$, due to a shear dilatation, and the annihilation rate $v_{f}$ due to diffusion, which can be described as follows [43]:

$$
\dot{x}=\frac{f}{a v^{*}} \exp \left(-\frac{\Delta G^{m}}{k T}\right) \exp \left(-\frac{1}{x}\right)\left\{\frac{2 k T}{S} \frac{1}{x}\left[\cosh \left(\frac{\tau \Omega}{2 k T}\right)-1\right]-\frac{v^{*}}{n_{D}}\right\}
$$

where $x$ is the ratio between the average free volume and the critical (hard-sphere) volume of one atom, $v^{*}$, i.e., $x=\frac{v_{f}}{\alpha v^{*}}$ [57]; $\dot{x}$ is the change rate of free volumes; $f$ is the Debye frequency, $\tau$ is the shear stress; $\alpha$ is a geometric factor between 0.5 and $1 ; k$ is the Boltzmann constant; $T$ is the temperature; $\Omega$ is the atomic volume $\left(\sim 1.25 v^{*}\right) ; \Delta G^{m}$ is the activation energy of the atomic motion; $S=\frac{2}{3} G \frac{1+\mu}{1-\mu}$, where $\mu$ is Poisson's ratio and $G$ is the shear modulus, $n_{D}$ is the number of atomic 
diffusive jumps needed to annihilate a free volume equaling to $v^{*}$, which is between 1 and 10 . The activation energy, $\Delta G^{m}$, can be determined by using the equation $\Delta G^{m}=\left(8 / \pi^{2}\right) G \gamma_{c}{ }^{2} \zeta \Omega_{\mathrm{s}}$ (where $\gamma_{c}=$ $0.026, \zeta=3$, and $\left.\Omega_{s}=2 v^{*}\right)$ [57].

With increasing the stress (or temperature), the free-volume fraction also increases, which results in the plastic flow (or glass transition) $[47,48,58]$. A numerical solution of Eq. (3) is required in order to quantitatively describe the free-volume evolution. In the present study, we choose twelve metallic glasses as the model materials, which are listed in Table II, to find a universal discipline. The dilatation of free volumes in the small fraction from 1.0 to $1.5 \%$ needs a geological timescale for atomic shifting [59], which is not self-consistent with experimental observations. Therefore, the start point of the $x$ value for the numerical calculation is set at 2.0\%. The $\alpha$ and $n_{D}$ values for all the metallic glasses are 1 and 5, respectively. The other parameters are also listed in Table II. The evolution time, $\tau_{\mathrm{R}}$, as a function of the free-volume fraction for the four metallic glasses are representatively shown in Fig. 6. For all the metallic glasses, the free-volume fraction can evolve to a critical value of $2.4 \%$, following which, the free-volume fraction increases dramatically, indicating the occurrence of viscous flow (or glass transition). The evolution times, $\tau_{R}$, of the metallic glasses are listed in Table II, which are all in the order of $10^{4}-10^{6} \mathrm{~s}$. The critical value of $2.4 \%$ is independent of the parameters of $n_{D}, \alpha$, and $x_{0}$, as well as the chemical compositions, which is universal for metallic glasses.

The occurrence of plastic flow indicates that some atomic clusters, such as shear transformation zones or flow units, shift to cooperate with the macroscopic-plastic deformation $[4,60]$. These atomic-clusters operation is associated with the $\alpha$ relaxation of the glassy phase because the plastic yield has already occurred after the free-volume fraction approaches the critical value [61]. In this case, the evolution time of free volumes under the stress is equivalent to the $\alpha$ relaxation time, $\tau_{c}$. For the $\alpha$-relaxation, the temperature dependence of $\tau_{c}$ is described by using the Vogel-Fulcher-Tammann (VFT) equation, $\tau_{c}=\tau_{0} \exp \left(\frac{B T_{0}}{T_{R}-T_{0}}\right)$, where $\tau_{0}$ is the prefactor $\left(\sim 10^{-13}\right)$, $B$ is the fragility parameter, $T_{0}$ is the VFT temperature [62,63], and $T_{R}$ is the deformation temperature. Based on the parameters listed in Table II, the deformation temperatures, $T_{R}$, for different metallic glasses are calculated and also listed in Table II. The deformation temperatures 
exactly equal the glass-transition temperatures, $T_{g}$, of metallic glasses. Consequently, the plastic yield of metallic glasses at room temperature is accompanied with the dramatic increase in free volumes, which is equivalent to the increase in the temperature to be the glass-transition temperature.

For the irradiated $\mathrm{Zr}_{50.7} \mathrm{Cu}_{28} \mathrm{Ni}_{9} \mathrm{Al}_{12.3}$ metallic glass, the parameters of the Debye frequency, $f$, cannot be obtained, thus the value we used is that of the sample without the irradiation. The critical volume of one atom can be deduced from the peak-position shift in the XRD patterns [Fig. 1(c)]. For the shear modulus and Poisson's ratio, the experimental measurements are not possible. The previous study has found that the increment of the elastic modulus due to the high-pressure compact is the same as that the increment of shear modulus [64], thus indicating that we can deduce the shear modulus and Poisson's ratio of the irradiated metallic glass according to the values of the metallic glass without irradiation. In the present study, after the irradiation at 0.5 $\mathrm{dpa}$, the volume dilatation results in the decrease in the elastic modulus to $108 \mathrm{GPa}$ that is $6 \%$ less than the value without the irradiation (Table I). It can be reasonably deduced that the shear modulus of the metallic glasses irradiated at $0.5 \mathrm{dpa}$ also decreased $6 \%$, compared to the value at $0 \mathrm{dpa}$. The values of the shear moduli of the metallic glass irradiated at $0.5,1$, and $5 \mathrm{dpa}$ are listed in Table II. The calculated evolution time is around $4.7 \times 10^{3} \mathrm{~s}$ that is much less than the value without irradiation $\left(1.9 \times 10^{5} \mathrm{~s}\right)$. According to the VFT equation, the deformation temperature for the metallic glass irradiated at $0.5 \mathrm{dpa}$ is approximately $735 \mathrm{~K}$, which is $16 \mathrm{~K}$ higher than the glass-transition temperature $(719 \mathrm{~K})$. In other words, the increase in the free volume indicates that the plastic flow occurs in the supercooled-liquid region rather than at the glass-transition temperature, which is manifested as low yield strength and good ductility, as confirmed by Figs. 3 and 4. The evolution time of the free volume and the deformation temperature of the metallic glass irradiated at $1 \mathrm{dpa}$ do not significantly change, compared to the values at $0.5 \mathrm{dpa}$. For the metallic glass at $5 \mathrm{dpa}$, the influence from the nano-crystalline phase is more serious relative to that at $1 \mathrm{dpa}$. Thus, discussion of the evolution of the free volume is unreasonable.

After yielding, the weak spots with a large number of free volumes act as the primary flow units to deliver the plastic strain in metallic glasses [60]. In this case, the free-volume fraction becomes a dominant factor influencing the shear-banding behavior [65]. The 
shear-banding behavior under nanoindenter can be manifested as the pop-in event in the loading stage of the nanoindentation tests, which indicates that the construction of a linkage between the shear-banding behavior and the pop-in events is significantly important for understanding the plastic mechanism of metallic glasses [66]. Based on the nanoindentation tests, Tönnies et al. reported that the initiation of shear-banding, i.e., the plastic deformation carried by free volume, was thermally activated with a rate- and stress-dependent activation volume based on a statistical analysis of the first pop-ins [44]. Enlightened by the previous study [44], a statistical analysis of the size of pop-ins in the loading stage of the nanoindentation tests is performed in the present study. Considering that the distribution of the strain bursts in the pop-ins is irregular and stochastic, ergodically processing of the strain-burst size is performed. The pop-ins, $\Delta h$, are marked in Fig. S11. Herein, we normalize $\Delta h$ by the depth, $h$, and, then, obtain the strain-burst size, $S(=\Delta h / h)$. The details of this method are summarized in Supplementary Figs. S4 and S11. Figure 7 shows the cumulative distributions of the strain-burst sizes, i.e., the percentage of the number of strain-burst sizes being larger than a given value, $C(>S)$, of four samples loaded at different rates. Two stages in the distributions are recognized in Fig. 7. Stage I constitutes numerous smaller strain bursts, which follows a power-law distribution. Stage II is composed of several larger strain bursts, in which the distribution of these strain bursts exhibits a fast decay. The cumulative distributions (consisting of Stages I and II) of four samples can be predicted by a power-law distribution function as follows [67]:

$$
\mathrm{C}(S) \sim S^{-(\kappa-1)} F\left(S / S_{C}\right)
$$
where $F\left(S / S_{C}\right)\left[=\exp \left(-\left(S / S_{C}\right)\right)\right]$ is a rapidly-decaying scaling function, $\kappa$ is a scaling exponent $(\kappa=$ 1.5 in the mean-field theory [68-70]), and $S_{C}$ is the size of the largest typical "critical" avalanche that acts as a cut-off in $F\left(S / S_{C}\right)$, and decays exponentially to the leading order for large $S / S_{C}>1$.

As shown in Fig. 7, the exponent, $\kappa$, of four samples is $1.2 \pm 0.1$, close to the mean-field value of 1.5, indicating that the inhomogeneous deformations of four samples are not influenced by the structural and/or loading-rate differences [71]. The theory of phase transitions has shown that the exponent, $\kappa$, depends only on the fundamental parameters, such as the basic symmetries and the effective dimensionality of the system, and is independent of the microscopic details related to the 
individual behavior of the interacting entities [72]. Thus, the exponents in four samples with

different structures exhibit a constant value of 1.2.

For the $S$ value near and above the critical avalanche value, $S_{C}$, the rapidly-decaying function, $F\left(S / S_{C}\right)$, in Eq. (4) dominates the scaling behavior of $C(S)$. The critical avalanche value, $S_{C}$, reflects the shear-avalanche behavior on large scale [73], and plays an important role in the rupture process of materials $[67,73,74]$. The $S_{C}$ value depends on the experimental tuning parameters, such as stress, strain rate, and temperature [67,71]. The elastic coupling between the shear-deformed weak spots generates a shear-avalanche, or a strain burst [68]. Once the shear deformation of the weak spots occurs, its localized shear stress is eventually weakened until the strain burst is completed $[72,75,76]$. This weakening effect leads to the formation of shear bands [76], indicating that the critical avalanche value is determined by the total stress drop per weak spot. Thus, the shear resistance for the operation of weak spots is required to be understood.

The micro-pillar compression and the evaluation of the evolution time for free volumes indicate that the irrigation of excess free volumes can effectively decrease the yield strength, i.e., the shear resistance of the weak-spot operation is decreased. The dependence of the critical shear-avalanche size, $S_{C}$, on the yield strength is plotted in Fig. 8. Evidently, with an increase in the yield strength, the critical avalanche value correspondingly increases. For the case at $0 \mathrm{dpa}$, after yielding, the weak spots cannot accommodate the shear strain, and, subsequently, react upon the elastic matrix, which brings out the shear-avalanche. The irradiation at 0.5 dpa generates more free volumes embedded into the glassy phase, in which the local failure threshold of the weak spots is weakened [76]. These sliding weak spots irrigated by excess free volumes can partition the accommodated shear strain, and, then, result in the smaller $S_{C}$ value, as compared to that at $0 \mathrm{dpa}$, and decreased yield strength. At $1 \mathrm{dpa}$, the size of the nano-particles $(\leq 5 \mathrm{~nm})$ is less than the width $(\sim 10 \mathrm{~nm})$ of shear bands but larger than the size of the weak spot, which indicates that the nano-particles can participate in (or obstruct) the shear rearrangement of the weak spots, but cannot stop shear banding. In this case, these small nano-particles may lead to re-strengthening of the existing weak spots but not influence the shear-banding process, and a greater stress is required to operate the enhanced weak spots compared to that at $0.5 \mathrm{dpa}$. Therefore, the values of yield strength and the $S_{C}$ value slightly increase (Fig. 8). At 5 dpa irradiation, the nano-crystals are enlarged to be 
approximately $10 \mathrm{~nm}$ in diameter, which is already comparable to the thickness of shear bands. The nano-crystals can prohibit shear sliding. A stress concentration can be easily built up at the interface between the crystalline and glassy phases [77]. When the stress concentration approaches the failure threshold of the weak spot, the shear bands commence to slip across the nano-crystal/glass interface. In this way, the plastic deformation originates from the interface, generating more shear bands, relative to those at 1 dpa [Fig. 3 (b)]. The increase in the shear-band density could partition the large strain burst, causing a reduction in the $S_{\mathrm{C}}$ value, as compared to the value at $1 \mathrm{dpa}$. Furthermore, since the interface of nano-crystals/glass can actually generate more shear bands upon the shear stress, the operation of shear banding is much easier relative to the cases at 0 and $1 \mathrm{dpa}$. The yield strength at 5 dpa decreases [Fig. 3(c)]. Accordingly, we can image that if the ion irradiation can modify the critical shear-avalanche value to be as low as possible, the intermittent shear-avalanche can be avoided, and the homogeneous plastic deformation can be consequently achieved [49].

\section{Conclusions}

Heavy ion irradiation can modify the structure of metallic glasses, which causes the dilatation of the glassy phase, and nano-crystallization. Through controlling the irradiation dosage, the amount of free volumes can be manipulated. At a low irradiation dosage, such as $0.5 \mathrm{dpa}$, the irradiation-induced viscous flow results in the homogeneity of the free volumes in the glassy phase, and simultaneously increases the free-volume fraction. Further increasing the irradiation dosage leads to the precipitation of the nano-particles embedded into the glassy phase. These nano-crystals, acting as inhomogeneous structures, deteriorate the homogeneity of the glassy phase, and influence the operation of weak spots, which then, dominates the mechanical behavior of the metallic glass. The compelling experimental evidences from the structural characterization, the micro-pillar compression tests, the in-situ TEM tension experiments, the nanoindentation tests, and the theoretical analysis based on the free-volume model indicate that the irradiation can increase the free-volume fraction, and then enhance the plastic deformation ability of metallic glasses. According to the mean-field theory $[69,70]$, the plastic deformation of the metallic glass is believed to proceed via slip avalanches of weak spots. The changes in the free-volume fraction can result in 
the variation of the local failure threshold of weak spots, which tunes the strain-burst statistics and the dynamic avalanche profiles. The present finding enlightens us that if an ion beam, with a low dosage, is able to modify the structure of the entire metallic-glass sample, the metallic glasses would possess an excellent and lucrative plastic-deformation ability at room temperature.

\section{Acknowledgments}

The work described in this paper was supported by grants from the MOST (No. 2015CB856804), NSF of China (Nos. 51171098, 51222102 and 11271339), the RGC of the Hong Kong (Nr. PolyU511211), the Program for Professor of Special Appointment (Eastern Scholar) at Shanghai Institutions of Higher Learning. PKL appreciates the financial support from the US National Science Foundation (DMR-0909037, CMMI-0900271, and CMMI-1100080), the Department of Energy (DOE), Office of Nuclear Energy's Nuclear Energy University Program (NEUP) 00119262, and the DOE, Office of Fossil Energy, National Energy Technology Laboratory (DE-FE-0008855 and DE-FE-0024054), and the U.S. Army Research Office Project (W911NF-13-1-0438) with C. Huber, C.V. Cooper, D. Finotello, A. Ardell, E. Taleff, V. Cedro, R. Dunst, R.O. Jensen, L. Tan, S.N. Mathaudhu, and S. Lesica as contact monitors. KAD and PKL thank DOE for support through project FE0011194 with the project managers, S. Markovich and D. Sterr. LY appreciates the strategic priority research program of TMSR (XDA02040100), and the China-Australia Joint Research Project (2014DFG60230).

\section{References}

[1] M.H. Cohen, D. Turnbull, Molecular transport in liquids and glasses, J. Chem. Phys. 31 (1959) 1164-1169.

[2] M.W. Chen, Mechanical behavior of metallic glasses: microscopic understanding of strength and ductility, Annu. Rev. Mater. Res. 38 (2008) 445-469.

[3] J. Ding, S. Patinet, M.L. Falk, Y.Q. Cheng, E. Ma, Soft spots and their structural signature in a metallic glass, Proc. Nat. Acad. Sci. U.S.A. 111 (2014) 14052-14056. 
[4] Y.H. Liu, D. Wang, K. Nakajima, W. Zhang, A. Hirata, T. Nishi, A. Inoue, M.W. Chen,

Characterization of nanoscale mechanical heterogeneity in a metallic glass by dynamic force microscopy, Phys. Rev. Lett. 106 (2011) 125504.

[5] M.J. Demkowicz, A.S. Argon, High-density liquidlike component facilitates plastic flow in a model amorphous silicon system, Phys. Rev. Lett. 93 (2004) 025505.

[6] J.C. Ye, J. Lu, C.T. Liu, Q. Wang, Y. Yang, Atomistic free-volume zones and inelastic deformation of metallic glasses, Nat. Mater. 9 (2010) 619-623.

[7] Y.H. Liu, G. Wang, R.J. Wang, D.Q. Zhao, M.X. Pan, W.H. Wang, Super plastic bulk metallic glasses at room temperature, Science 315 (2007) 1385-1388.

[8] H. Wagner, D. Bedorf, S. Küchemann, M. Schwabe, B. Zhang, W. Arnold, K. Samwer, Local elastic properties of a metallic glass, Nat. Mater. 10 (2011) 439-442.

[9] C. Fan, P.K. Liaw, C.T. Liu, Atomic model of amorphous materials, Intermetallics 17 (2009) 86-87.

[10] C. Fan, P.K. Liaw, T.W. Wilson, W. Dmowski, H. Choo, C.T. Liu, J.W. Richardson, Th. Proffen, Structural model for bulk amorphous alloys, Appl. Phys. Lett. 89, (2006) 111905.

[11] G.Y. Wang, P.K. Liaw, W.H. Peter, B. Yang, Y. Yokoyama, M.L. Benson, B.A. Green, M.J. Kirkham, S.A. White, T.A. Saleh, R.L. McDaniels, R.V. Steward, R.A. Buchanan, C.T. Liu, C.R. Brooks, Fatigue behavior of bulk-metallic glasses, Intermetallics 12 (2004) 885-892.

[12] W.H. Peter, P.K. Liaw, R.A. Buchanan, C.T. Liu, C.R. Brooks, J.A. Horton Jr, C.A. Carmichael Jr, J.L. Wright, Fatigue behavior of $\mathrm{Zr}_{52.5} \mathrm{Al}_{10} \mathrm{Ti}_{5} \mathrm{Cu}_{17.9} \mathrm{Ni}_{14.6}$ bulk metallic glass, Intermetallics 10 (2002) 1125-1129.

[13] T. Fujita, P.F. Guan, H.W. Sheng, A. Inoue, T. Sakurai, M.W. Chen, Coupling between chemical and dynamic heterogeneities in a multicomponent bulk metallic glass. Phys, Rev. B 81 (2010) 140204(R).

[14] H. Shintani, H. Tanaka, Frustration on the way to crystallization in glass, Nat. Phys. 2 (2006) 200-206.

[15] C.A. Schuh, T.C. Hufnagel, U. Ramamurty, Mechanical behavior of amorphous alloys, Acta Mater. 55 (2007) 4067-4109. 
[16] D.R. Maddala, R.J. Hebert, Sliding wear behavior of $\mathrm{Fe}_{50-\mathrm{x}} \mathrm{Cr}_{15} \mathrm{Mo}_{14} \mathrm{C}_{15} \mathrm{~B}_{6} \mathrm{Er}_{\mathrm{x}}(\mathrm{x}=0,1,2$ at \%) bulk metallic glass, Wear 294-295 (2012) 246-256.

[17] M.L. Rahaman, L.C. Zhang, H.H. Ruan, Understanding the friction and wear mechanisms of bulk metallic glass under contact sliding, Wear 304 (2013) 43-48.

[18] M.D. Archer, C.C. Corke, B.H. Harji, The electrochemical properties of metallic glasses, Electrochim. Acta. 32 (1987) 13-26.

[19] U.K. Mudali, S. Baunack, J. Eckert, L. Schultz, A. Gebert, Pitting corrosion of bulk glass-forming zirconium-based alloys, J. Alloys. Compd. 377 (2004) 290-297.

[20] W.H. Peter, R.A. Buchanan, C.T. Liu, P.K. Liaw, M.L. Morrison, J.A. Horton, C.A. Carmichael Jr, J.L. Wright, Localized corrosion behavior of a zirconium-based bulk metallic glass relative to its crystalline state, Intermetallics 10 (2002) 1157-1162.

[21] M.L. Morrison, R.A. Buchanan, A. Peker, W.H. Peter, J.A. Horton, P.K. Liaw, Cyclic-anodic-polarization of a $\mathrm{Zr}_{41.2} \mathrm{Ti}_{13.8} \mathrm{Ni}_{10} \mathrm{Cu}_{12.5} \mathrm{Be}_{22.5}$ bulk metallic glass, Intermetallics 12 (2004) 1177-1181.

[22] M.L. Morrison, R.A. Buchanan, R.V. Leon, C.T. Liu, B.A. Green, P.K. Liaw, J.A. Horton, The electrochemical evaluation of a Zr-based bulk metallic glass in a phosphate-buffered saline electrolyte, J. Biomed. Mater. Res. A 74A (2005) 430-438.

[23] Y. Zhang, W.H. Wang, A.L. Greer, Making metallic glasses plastic by control of residual stress, Nat. Mater. 5 (2006) 857-860.

[24] Y. Cao, X. Xie, J. Antonaglia, B. Winiarski, G. Wang, Y.C. Shin, Y.C. Shin, P.J. Withers, K.A. Dahmen, P.K. Liaw, Laser shock peening on Zr-based bulk metallic glass and its effect on plasticity: experiment and modeling, Sci. Rep. 5 (2015) 10789.

[25] A.P. Radliński, A. Calka, B. Luther-Davies, Modification of $\mathrm{Pd}_{77} \mathrm{Si}_{23}$ metallic glasses by picosecond laser annealing, Phys. Rev. Lett. 57 (1986) 3081.

[26] S.G. Mayr, R.S. Averback, Surface smoothing of rough amorphous films by irradiation-induced viscous flow, Phys. Rev. Lett. 87 (2001) 196106.

[27] S.G. Mayr, Impact of ion irradiation on the thermal, structural, and mechanical properties of metallic glasses, Phys. Rev. B 71 (2005) 144109. 
[28] T. Steinbach, C.S. Schnohr, P. Kluth, R. Giulian, L.L. Araujo, D.J. Sprouster, M.C. Ridgway, W.

Wesch, Influence of electronic energy deposition on the structural modification of swift heavy-ion-irradiated amorphous germanium layers, Phys. Rev. B 83 (2011) 054113.

[29] M.C. Ridgway, T. Bierschenk, R. Giulian, B. Afra, M.D. Rodriguez, L.L. Araujo, A.P. Byrne, N. Kirby, O.H. Pakarinen, F. Djurabekova, K. Nordlund, M. Schleberger, O. Osmani, N. Medvedev, B. Rethfeld, P. Kluth, Tracks and voids in amorphous Ge induced by swift heavy-ion irradiation, Phys. Rev. Lett. 110 (2013) 245502.

[30] M. Nastasi, J.W. Mayer, J.K. Hirvonen, Ion-Solid Interactions: Fundamentals and Applications, Cambridge University Press, New York, 1996.

[31] J. Carter, E.G. Fu, M. Martin, G.Q. Xie, X. Zhang, Y.Q. Wang, D. Wijesundera, X.M. Wang, W.K. Chu, S.M. McDeavitt, L. Shao, Ion irradiation induced nanocrystal formation in amorphous $\mathrm{Zr}_{55} \mathrm{Cu}_{30} \mathrm{Al}_{10} \mathrm{Ni}_{5}$ alloy, Nucl. Instrum. Methods Phys. Res., Sect. B 267 (2009) 2827-2831.

[32] M. Myers, E.G. Fu, M. Myers, H. Wang, G.Q. Xie, X. Wang, W.K. Chu, L. Shao, An experimental and modeling study on the role of damage cascade formation in nanocrystalization of ion-irradiated $\mathrm{Ni}_{52.5} \mathrm{Nb}_{10} \mathrm{Zr}_{15} \mathrm{Ti}_{15} \mathrm{Pt}_{7.5}$ metallic glass, Scr. Mater. 63 (2010) 1045-1048.

[33] J. Carter, E.G. Fu, M. Martin, G.Q. Xie, X. Zhang, Y.Q. Wang, D. Wijesundera, X.M. Wang, W.K. Chu, L. Shao, Effects of $\mathrm{Cu}$ ion irradiation in $\mathrm{Cu}_{50} \mathrm{Zr}_{45} \mathrm{Ti}_{5}$ metallic glass, Scr. Mater. 61 (2009) 265-268.

[34] W. Qin, J.A. Szpunar, Y. Umakoshi, Electron or ion irradiation-induced phase-change mechanism between amorphous and crystalline state, Acta Mater. 59 (2011) 2221-2228.

[35] K.A. Avchaciov, Y. Ritter, F. Djurabekova, K. Nordlund, K. Albe, Controlled softening of $\mathrm{Cu}_{64} \mathrm{Zr}_{36}$ metallic glass by ion irradiation, Appl. Phys. Lett. 102 (2013) 181910.

[36] R. Raghavan, B. Kombaiah, M. Döbeli, R. Erni, U. Ramamurty, J. Michler, Nanoindentation response of an ion irradiated Zr-based bulk metallic glass, Mat. Sci. Eng. A 532 (2012) 407-413.

[37] D.J. Magagnosc, G. Kumar, J. Schroers, P. Felfer, J.M. Cairney, D.S. Gianola, Effect of ion irradiation on tensile ductility, strength and fictive temperature in metallic glass nanowires, Acta Mater. 74 (2014) 165-182.

[38] M. Iqbal, A. Qayyum, J.I. Akhter, Surface modification of Zr-based bulk amorphous alloys by using ion irradiation, J. Alloy. Compd. 509 (2011) 2780-2783. 
[39] R. Raghavan, K. Boopathy, R. Ghisleni, M.A. Pouchon, U. Ramamurty, J. Michler, Ion

irradiation enhances the mechanical performance of metallic glasses, Scr. Mater. 62 (2010) 462-465.

[40] E. Menéndez, A. Hynowska, J. Fornell, S. Suriñach, J. Montserrat, K. Temst, J. Sort, Influence of the irradiation temperature on the surface structure and physical/chemical properties of Ar ion-irradiated bulk metallic glasses, J. Alloys. Compd. 610 (2014) 118-125.

[41] W.D. Luo, B. Yang, G.L. Chen, Effect of Ar+ ion irradiation on the microstructure and properties of Zr-Cu-Fe-Al bulk metallic glass, Scr. Mater. 64 (2011) 625-628.

[42] Z.W. Zhang, C.T. Liu, X.L. Wang, M.K. Miller, D. Ma, G. Chen, J.R. Williams, B.A. Chin, Effects of proton irradiation on nanocluster precipitation in ferritic steel containing fcc alloying additions, Acta Mater. 60 (2012) 3034-3046.

[43] F. Spaepen, A microscopic mechanism for steady state inhomogeneous flow in metallic glasses, Acta Metall. 25 (1977) 407-415.

[44] D. Tönnies, K. Samwer, P.M. Derlet, C.A. Volkert, R. Maaß, Rate-dependent shear-band initiation in a metallic glass, Appl. Phys. Lett. 106 (2015) 171907.

[45] J. Tan, G. Wang, Z.Y. Liu, J. Bednarčík, Y.L. Gao, Q.J. Zhai, N. Mattern, J. Eckert, Correlation between atomic structure evolution and strength in a bulk metallic glass at cryogenic temperature, Sci. Rep. 4 (2014) 3897(1-7).

[46] A.R. Yavari, A. Le Moulec, A. Inoue, N. Nishiyama, N. Lupu, E. Matsubara, W.J. Botta, G. Vaughan, M.D. Michiel, Å. Kvick, Excess free volume in metallic glasses measured by X-ray diffraction, Acta Mater. 53 (2005) 1611-1619.

[47] P.E. Donovan, W.M. Stobbs, The structure of shear bands in metallic glasses, Acta Metall. 29 (1981) 1419-1436.

[48] K. Hajlaoui, T. Benameur, G. Vaughan, A.R. Yavari, Thermal expansion and indentation-induced free volume in $\mathrm{Zr}$-based metallic glasses measured by real-time diffraction using synchrotron radiation, Scr. Mater. 51 (2004) 843-848.

[49] X.Y. Zhao, D.J. Strickland, P.M. Derlet, M.R. He, Y.J. Cheng, J. Pu, K. Hattar, D.S. Gianola, In situ measurements of a homogeneous to heterogeneous transition in the plastic response of ion-irradiated <111> Ni microspecimens, Acta Mater. 88 (2015) 121-135. 
[50] W. Zheng, Y.J. Huang, G.Y. Wang, P.K. Liaw, J. Shen, Influence of strain rate on compressive

deformation behavior of a $\mathrm{Zr}-\mathrm{Cu}-\mathrm{Ni}-\mathrm{Al}$ bulk metallic glass at room temperature, Metall. Mater. Trans. A 42 (2011) 1491-1498.

[51] D. Jang, J.R. Greer, Transition from a strong-yet-brittle to a stronger-and-ductile state by size reduction of metallic glasses, Nat. Mate. 9(3) (2010) 215-219.

[52] B. Poon, D. Rittel, G. Ravichandran, An analysis of nanoindentation in linearly elastic solids, Int. J. Solids. Struct. 45 (2008) 6018-6033.

[53] W. Weibull, A statistical distribution function of wide applicability, J. Appl. Mech. 18 (1951) 293-297.

[54] B. Zberg, E.R. Arata, P.J. Uggowitzer, J.F. Löffler, Tensile properties of glassy MgZnCa wires and reliability analysis using Weibull statistics, Acta Mater. 57 (2009) 3223-3231.

[55] J.F. Ziegler, J.P. Biersack, U. Littmark, The stopping and range of ions in matter, Springer US, 1985 pp. 93-129.

[56] C.H. Lai, C.H. Yang, C.C. Chiang, Ion-irradiation-induced direct ordering of L10 FePt phase. Appl. Phys. Lett. 83 (2003) 4550-4552.

[57] W.L. Johnson, K. Samwer, A universal criterion for plastic yielding of metallic glasses with a $\left(\mathrm{T} / \mathrm{T}_{\mathrm{g}}\right)^{2 / 3}$ temperature dependence, Phys. Rev. Lett. 95 (2005) 195501.

[58] C. Nagel, K. Rätzke, E. Schmidtke, J. Wolff, U. Geyer, F. Faupel, Free-volume changes in the bulk metallic glass $\mathrm{Zr}_{46.7} \mathrm{Ti}_{8.3} \mathrm{Cu}_{7.5} \mathrm{Ni}_{10} \mathrm{Be}_{27.5}$ and the undercooled liquid, Phys. Rev. B 57 (1998) 10224.

[59] J.G. Wang, D.Q. Zhao, M.X. Pan, W.H. Wang, S.X. Song, T.G. Nieh, Correlation between onset of yielding and free volume in metallic glasses, Scr. Mater. 62 (2010) 477-480.

[60] Z. Lu, W. Jiao, W.H. Wang, H.Y. Bai, Flow unit perspective on room temperature homogeneous plastic deformation in metallic glasses, Phys. Rev. Lett. 113 (2014) 045501.

[61] Z. Wang, B.A. Sun, H.Y. Bai, W.H. Wang, Evolution of hidden localized flow during glass-to-liquid transition in metallic glass, Nat. Commun. 5 (2014) 5823.

[62] C.A. Angell, K.L. Ngai, G.B. McKenna, P.F. McMillan, S.W. Martin, Relaxation in glass forming liquids and amorphous solids, J. Appl. Phys. 88 (2000) 3113-3157. 
[63] L. Hu, F. Ye, Y.F. Liang, J.P. Lin, Correlating the supercooled liquid region width with the fragility parameter in bulk metallic glasses, Appl. Phys. Lett. 100 (2012) 021906.

[64] J.Q. Wang, W.H. Wang, H.B. Yu, H.Y. Bai, Correlations between elastic moduli and molar volume in metallic glasses, Appl. Phys. Lett. 94 (2009) 121904.

[65] A. Dubach, K. Eswar Prasad, R. Raghavan, J.F. Löffler, J. Michler, U. Ramamurty, Free-volume dependent pressure sensitivity of Zr-based bulk metallic glass, J. Mater. Res. 24 (2009) 2697-2704.

[66] B. Moser, J. Kuebler, H. Meinhard, W. Muster, J. Michler, Observation of Instabilities during Plastic Deformation by in-situ SEM Indentation Experiments, Adv. Eng. Mater. 7 (2005) 388-392.

[67] T. Richeton, J. Weiss, F. Louchet, Breakdown of avalanche critical behavior in polycrystalline plasticity, Nat. Mater. 4 (2005) 465-469.

[68] J. Antonaglia, X. Xie, G. Schwarz, M. Wraith, J.W. Qiao, Y. Zhang, P.K. Liaw, J.T. Uhl, K.A. Dahmen, Tuned critical avalanche scaling in bulk metallic glasses, Sci. Rep. 4 (2014) 4382(1-5).

[69] K.A. Dahmen, Y. Ben-Zion, J.T. Uhl, A simple analytic theory for the statistics of avalanches in sheared granular materials, Nat. Phys. 7 (2011) 554-557.

[70] K.A. Dahmen, Y. Ben-Zion, J.T. Uhl, Micromechanical model for deformation in solids with universal predictions for stress-strain curves and slip avalanches, Phys. Rev. Lett. 102 (2009) 175501.

[71] X.L. Bian, G. Wang, K.C. Chan, J.L. Ren, Y.L. Gao, Q.J. Zhai, Shear avalanches in metallic glasses under nanoindentation: deformation units and rate dependent strain burst cut-off, Appl. Phys. Lett. 103 (2013) 101907.

[72] R.A. White, K.A. Dahmen, Driving rate effects on crackling noise, Phys. Rev. Lett. 91 (2003) 085702.

[73] M. Zaiser, P. Moretti, Fluctuation phenomena in crystal plasticity-a continuum model, J. Stat. Mech. (2005) P08004.

[74] S. Papanikolaou, D.M. Dimiduk, W.S. Choi, J.P. Sethna, M.D. Uchic, C.F. Woodward, S. Zapperi, Quasi-periodic events in crystal plasticity and the self-organized avalanche oscillator, Nature 419 (2012) 517-522. 
[75] J.Y. Kim, X. Gu, M. Wraith, J.T. Uhl, K.A. Dahmen, J.R. Greer, Suppression of catastrophic

failure in metallic glass-polyisoprene nanolaminate containing nanopillars, Adv. Funct. Mater. 22 (2012) 1972-1980.

[76] J. Antonaglia, W.J. Wright, X.J. Gu, R.R. Byer, T.C. Hufnagel, M. LeBlanc, J.T. Uhl, K.A. Dahmen, Bulk metallic glasses deform via slip avalanches, Phys. Rev. Lett. 112 (2014) 155501. [77] D.H. Kirkwood, Semisolid metal processing, Int. Mater. Rev. 39 (1994) 173-189. 


\section{Figure Captions:}

Fig. 1 Micro-area XRD patterns. (a) Micro-area XRD patterns of the $\mathrm{Zr}_{50.7} \mathrm{Cu}_{28} \mathrm{Ni}_{9} \mathrm{Al}_{12.3}$ metallic glass irradiated at different dosages, and comparison of the difference curves for the metallic glass at different dosages (Difference curves are multiplied by a factor of 3). (b) Illustration of diffuse peak fitting for the $\mathrm{Zr}_{50.7} \mathrm{Cu}_{28} \mathrm{Ni}_{9} \mathrm{Al}_{12.3}$ metallic glass irradiated at $1 \mathrm{dpa}$. The open scattering points correspond to the experimental data. The red solid line is the fitting curve by a pseudo-Voigt function. (c) FWHM and peak position as a function of the irradiation dosage.

Fig. 2 TEM of the $\mathrm{Zr}_{50.7} \mathrm{Cu}_{28} \mathrm{Ni}_{9} \mathrm{Al}_{12.3}$ metallic glass irradiated at different dosages. (a), (d), (g), and (j) (Left column) Bright-field images. Insets show the SAED patterns. (b), (e), (h), and (k) (Middle column) High-resolution TEM images. (c), (f), (i), and (l) (Right column) FFT patterns corresponding to the regions covered by the white rectangles in the high-resolution images (Middle column).

Fig. 3 SEM images of the as-fabricated micro-pillars before and after compression tests shown in (a) and (b), respectively. (c) Representative stress-strain curves of the micro-pillars under different irradiation dosages. The stress is calculated by: $4 P /\left[\pi\left(D_{0}+2 d \tan \theta\right)^{2}\right]$ where $P$ is the load, $D_{0}$ is the tip diameter, $d$ is the tip displacement, and $\theta$ is the taper angle. (d) Determination of yield strength. Stress-strain curve of the metallic glass without irradiation is plotted. Dash line is a linearly fitting curve for the elastic deformation stage. Arrow points to the yield point. Inset shows the enlarged yield point.

Fig. 4 In-situ TEM tension tests. Sequences of TEM images for the strained metallic glass irradiated at different doasges. (a) $0 \mathrm{dpa}$, (b) $0.5 \mathrm{dpa}$, (c) $1 \mathrm{dpa}$, and (d) $5 \mathrm{dpa}$.

Fig. 5 Representative load-displacement $(P-h)$ curves of the nanoindentation tests. (a) The curves of the $\mathrm{Zr}_{50.7} \mathrm{Cu}_{28} \mathrm{Ni}_{9} \mathrm{Al}_{12.3}$ metallic glass irradiated at different dosages and a loading rate of $1 \mathrm{mN} \mathrm{s}^{-1}$. (b) Enlarged $P$ - $h$ curves in the loading stage, which correspond to the curves covered by a rectangle 
in (a). (c) The curves of the $\mathrm{Zr}_{50.7} \mathrm{Cu}_{28} \mathrm{Ni}_{9} \mathrm{Al}_{12.3}$ metallic glass loaded at different rates and at a dosage of $0.5 \mathrm{dpa}$. (d) Enlarged $P$ - $h$ curves in the loading stage, which correspond to the curves covered by a rectangle in (c). (e) Hardness value as a function of the irradiation dosage. The scatter points are the experimental data measured from forty nanoindentations. The averaged hardness value as a function of the irradiation dosage is also plotted. (f) Weibull plots of the hardness values taken from forty nanoindentations of the $\mathrm{Zr}_{50.7} \mathrm{Cu}_{28} \mathrm{Ni}_{9} \mathrm{Al}_{12.3}$ metallic glass irradiated at different dosages.

Fig. 6 The relaxation time as a function of the volume fraction of free volume of four representative metallic glasses, i.e., $\mathrm{Mg}_{65} \mathrm{Cu}_{25} \mathrm{Gd}_{10}, \mathrm{Cu}_{46} \mathrm{Zr}_{42} \mathrm{Al}_{7} \mathrm{Y}_{5}, \mathrm{Zr}_{50.7} \mathrm{Cu}_{28} \mathrm{Ni}_{9} \mathrm{Al}_{12.3}$, and $\mathrm{Ni}_{60} \mathrm{Nb}_{27.2} \mathrm{Ta}_{6.8} \mathrm{Sn}_{6}$ metallic glasses, strained at the yield stress.

Fig. 7 Cumulative distribution function of the strain-burst sizes for the $\mathrm{Zr}_{50.7} \mathrm{Cu}_{28} \mathrm{Ni}_{9} \mathrm{Al}_{12.3}$ metallic glass irradiated at different dosages. Open scatter points represent the experimental results measured from the $P$ - $h$ curves in the loading stage. Solid lines are fitting curves obtained by using Eq. (4). Dashed lines indicate the boundary between region I and region II.

Fig. 8 The average cut-off values at different irradiation dosages as a function of yield strength of the metallic glass irradiated at different dosages. 
Table I Hardness $(H)$ and elastic modulus $(E)$ of the Zr-based metallic glass under different irradiation dosages and averaged cut-off value $\left(S_{C}\right)$ determined by nanoindentation. Yield strength, $\sigma_{y}$, obtained from micro-pillar compression tests is also included.

\begin{tabular}{ccccc}
\hline Irradiation dosage (dpa) & $H(\mathrm{GPa})$ & $E(\mathrm{GPa})$ & $S_{C}$ & $\sigma_{y}(\mathrm{GPa})$ \\
\hline 0 & $7.64 \pm 0.32$ & $115 \pm 3$ & $6.98 \times 10^{-3}$ & $2.23 \pm 0.03$ \\
0.5 & $6.55 \pm 0.18$ & $108 \pm 2$ & $5.37 \times 10^{-3}$ & $1.77 \pm 0.05$ \\
1 & $6.35 \pm 0.24$ & $103 \pm 2$ & $6.53 \times 10^{-3}$ & $1.88 \pm 0.05$ \\
5 & $6.51 \pm 0.22$ & $108 \pm 2$ & $6.12 \times 10^{-3}$ & $1.84 \pm 0.05$ \\
\hline
\end{tabular}


Table II Summary of data on alloy compositions and properties used for calculations of the deformation temperature, $T_{R}$ and relaxation time, $\tau_{R}$. The average atomic volume, $v^{*}$; Debye frequency, $f$; Poisson's ratio, $\mu$; shear modulus, $G$; fragility parameter, $B$; VFT temperature, $T_{0}$; and glass-transition temperature, $T_{g}$. (Refs. 56-58, 62)

\begin{tabular}{|c|c|c|c|c|c|c|c|c|c|c|c|}
\hline Alloy Composition & $\begin{array}{c}v^{*} \\
\left(10^{-29} \mathrm{~m}^{3}\right)\end{array}$ & $\begin{array}{c}f \\
\left(10^{12} \mathrm{~Hz}\right)\end{array}$ & $\mu$ & $\begin{array}{c}G \\
(\mathrm{GPa})\end{array}$ & $\begin{array}{c}\sigma_{y} \\
(\mathrm{GPa})\end{array}$ & $B$ & $T_{0}(\mathrm{~K})$ & $\begin{array}{c}T_{g} \\
(\mathrm{~K}) \\
\end{array}$ & $\begin{array}{c}T_{R} \\
(\mathrm{~K})\end{array}$ & $T_{R} / T_{g}$ & $\begin{array}{c}\tau_{\mathrm{R}} \\
\left(10^{5} \mathrm{~s}\right)\end{array}$ \\
\hline $\mathrm{La}_{55} \mathrm{Al}_{25} \mathrm{Cu}_{10} \mathrm{Ni}_{5} \mathrm{Co}_{5}$ & 2.639 & 3.8 & 0.342 & 15.6 & 0.85 & 27.6 & 264 & 465 & 431 & 0.93 & 7.2 \\
\hline $\mathrm{Mg}_{65} \mathrm{Cu}_{25} \mathrm{Gd}_{10}$ & 1.949 & 5.5 & 0.320 & 18.6 & 0.98 & 15 & 260 & 410 & 350 & 0.85 & 6.0 \\
\hline $\mathrm{Pt}_{60} \mathrm{Ni}_{15} \mathrm{P}_{25}$ & 1.413 & 4.3 & 0.420 & 33.8 & 1.40 & 8.8 & 405 & 500 & 486 & 0.97 & 14.9 \\
\hline $\mathrm{Cu}_{46} \mathrm{Zr}_{42} \mathrm{Al}_{7} \mathrm{Y}_{5}$ & 1.698 & 5.6 & 0.364 & 31.0 & 1.60 & 2.7 & 623 & 675 & 662 & 0.98 & 4.2 \\
\hline $\mathrm{Pd}_{77.5} \mathrm{Cu}_{6} \mathrm{Si}_{16.5}$ & 1.452 & 5.0 & 0.409 & 31.8 & 1.50 & 11.1 & 493 & 637 & 618 & 0.97 & 8.5 \\
\hline $\mathrm{Zr}_{57.5} \mathrm{Nb}_{5} \mathrm{Cu}_{15.5} \mathrm{Ni}_{12} \mathrm{Al}_{10}$ & 1.959 & 5.7 & 0.379 & 30.8 & 1.58 & 11.3 & 524.7 & 663 & 663 & 1.00 & 3.6 \\
\hline $\mathrm{Pd}_{40} \mathrm{Cu}_{30} \mathrm{Ni}_{10} \mathrm{P}_{20}$ & 1.319 & 5.7 & 0.399 & 34.5 & 1.72 & 9.25 & 447 & 593 & 543 & 0.92 & 6.3 \\
\hline $\mathrm{Zr}_{46.75} \mathrm{Ti}_{8.25} \mathrm{Cu}_{7.5} \mathrm{Ni}_{10} \mathrm{Be}_{27.5}$ & 1.648 & 6.8 & 0.359 & 35.2 & 1.83 & 22.7 & 372 & 590 & 570 & 0.97 & 2.9 \\
\hline $\mathrm{Zr}_{41.2} \mathrm{Ti}_{13.8} \mathrm{Ni}_{10} \mathrm{Cu}_{12.5} \mathrm{Be}_{22.5}$ & 1.690 & 6.5 & 0.352 & 34.1 & 1.86 & 18.5 & 412.5 & 625 & 593 & 0.95 & 2.6 \\
\hline $\mathrm{Zr}_{55} \mathrm{Al}_{19} \mathrm{Co}_{19} \mathrm{Cu}_{7}$ & 1.900 & 6.4 & 0.352 & 37.6 & 2.20 & 12.2 & 576 & 733 & 744 & 1.02 & 1.4 \\
\hline $\mathrm{Ni}_{60} \mathrm{Nb}_{27.2} \mathrm{Ta}_{6.8} \mathrm{Sn}_{6}$ & 1.436 & 7.3 & 0.357 & 59.4 & 3.50 & 19 & 581 & 875 & 848 & 0.97 & 0.8 \\
\hline $\mathrm{Ni}_{60} \mathrm{Nb}_{35} \mathrm{Sn}_{5}$ & 1.416 & 8.0 & 0.385 & 66.3 & 3.85 & 11 & 670 & 885 & 849 & 0.96 & 0.7 \\
\hline $\mathrm{Zr}_{50.7} \mathrm{Cu}_{28} \mathrm{Ni}_{9} \mathrm{Al}_{12.3}(0 \mathrm{dpa})$ & 1.768 & 5.5 & 0.356 & 38.5 & 2.23 & 12 & 560 & 719 & 720 & 1.00 & 1.9 \\
\hline $\mathrm{Zr}_{50.7} \mathrm{Cu}_{28} \mathrm{Ni}_{9} \mathrm{Al}_{12.3}(0.5 \mathrm{dpa})$ & 1.779 & 5.5 & 0.355 & 36.2 & 1.77 & 12 & 560 & 719 & 735 & 1.02 & 0.05 \\
\hline $\mathrm{Zr}_{50.7} \mathrm{Cu}_{28} \mathrm{Ni}_{9} \mathrm{Al}_{12.3}(1 \mathrm{dpa})$ & 1.780 & 5.5 & 0.355 & 36.2 & 1.88 & 12 & 560 & 719 & 735 & 1.02 & 0.05 \\
\hline
\end{tabular}


FIG 1
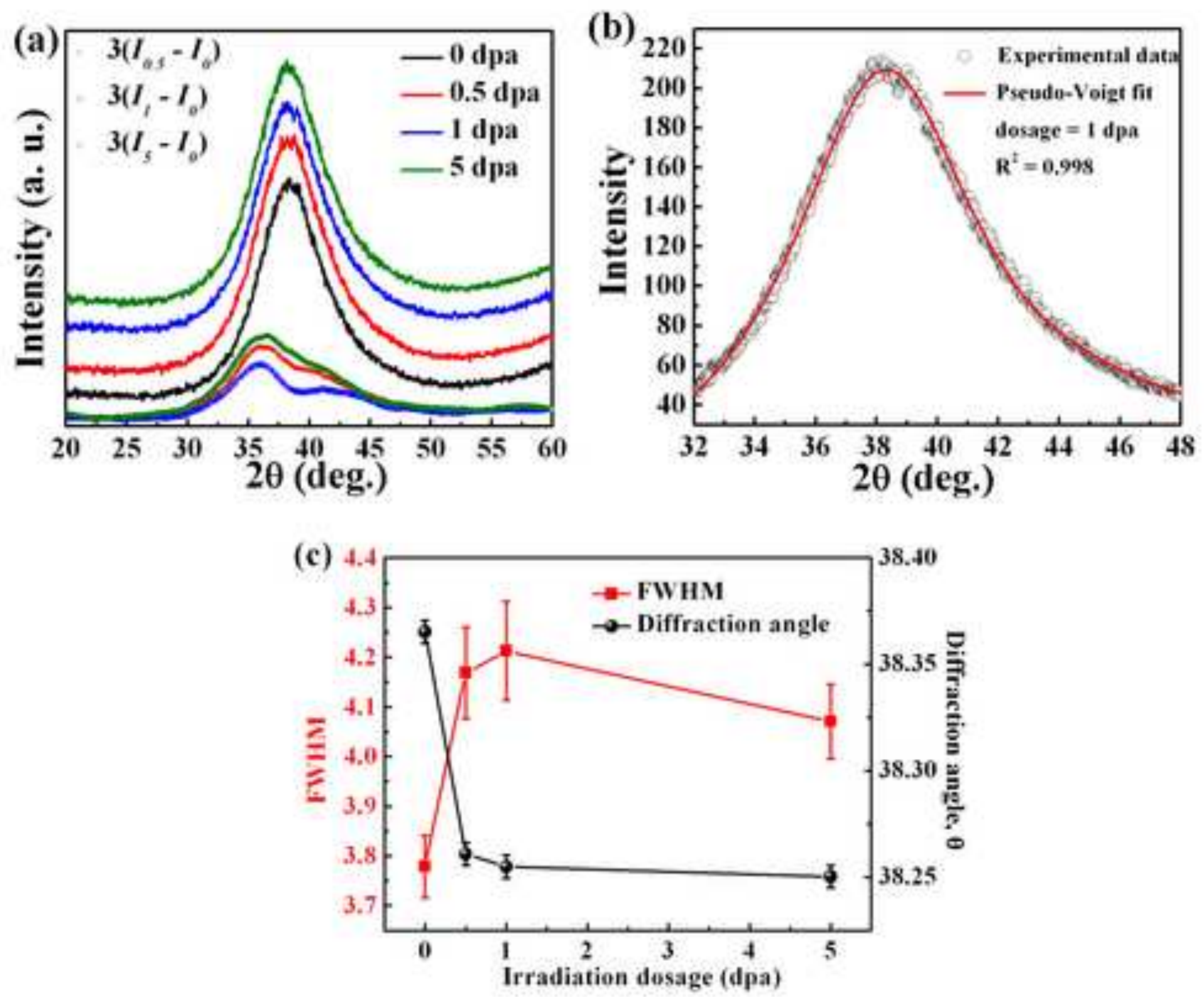


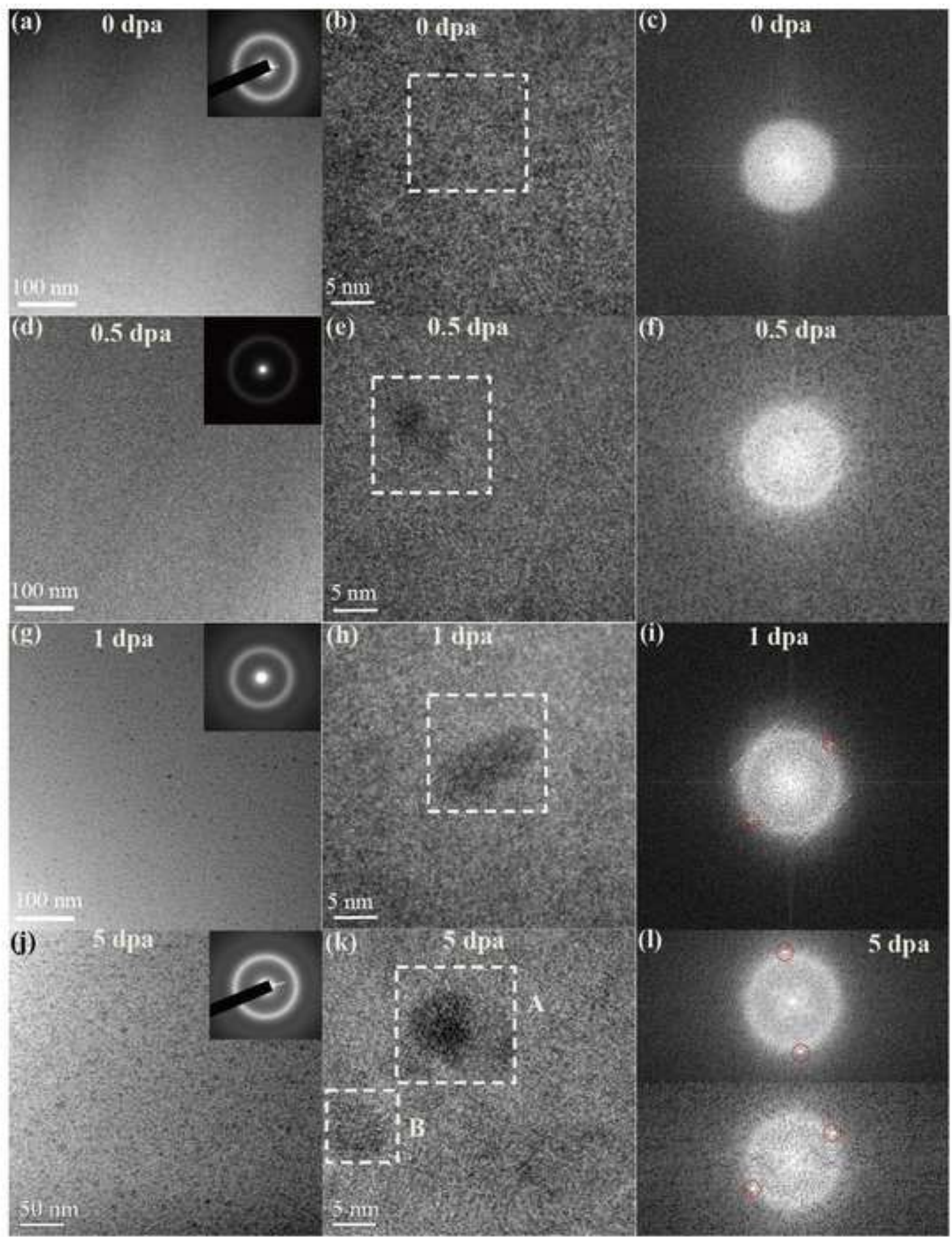



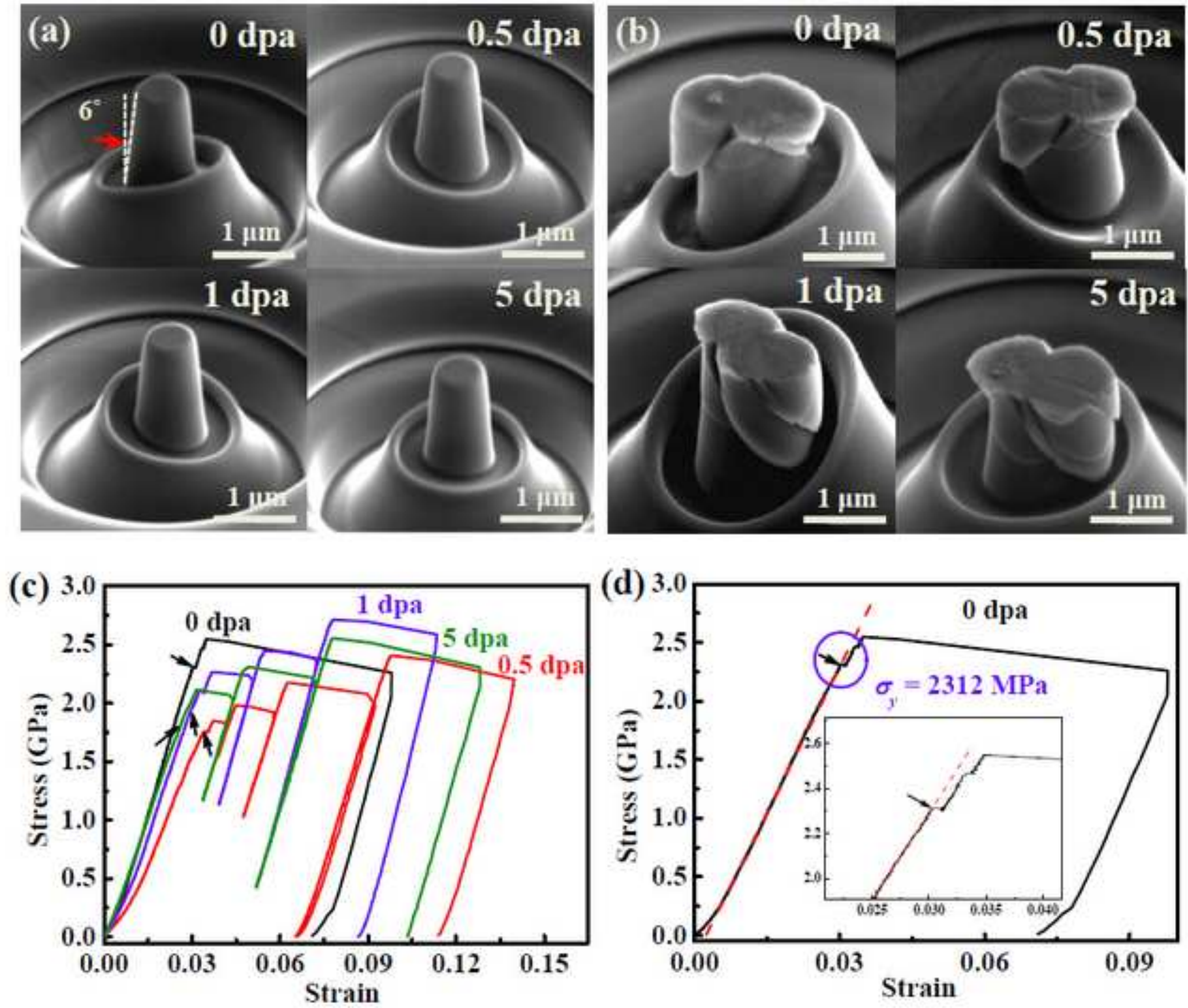


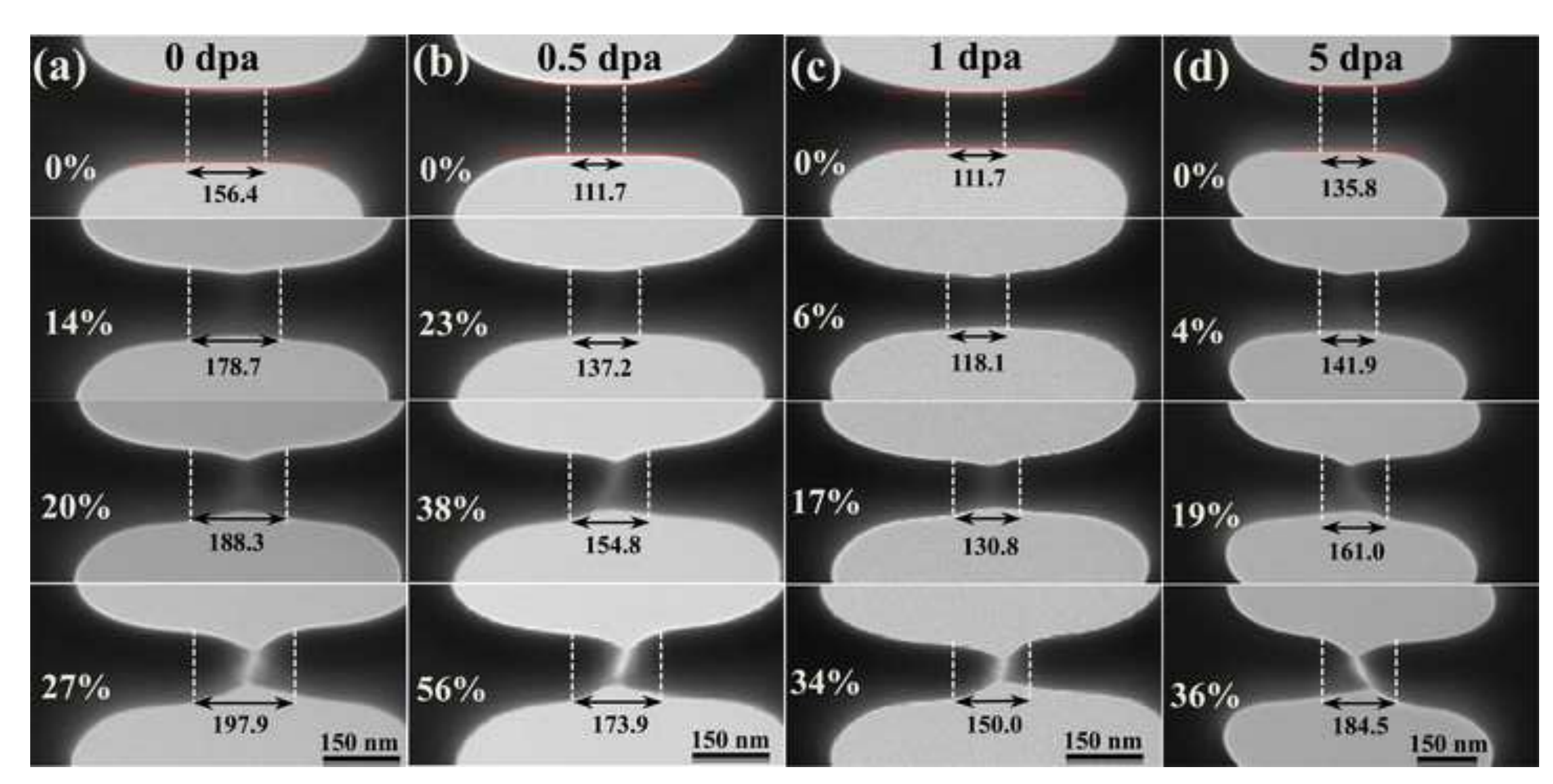



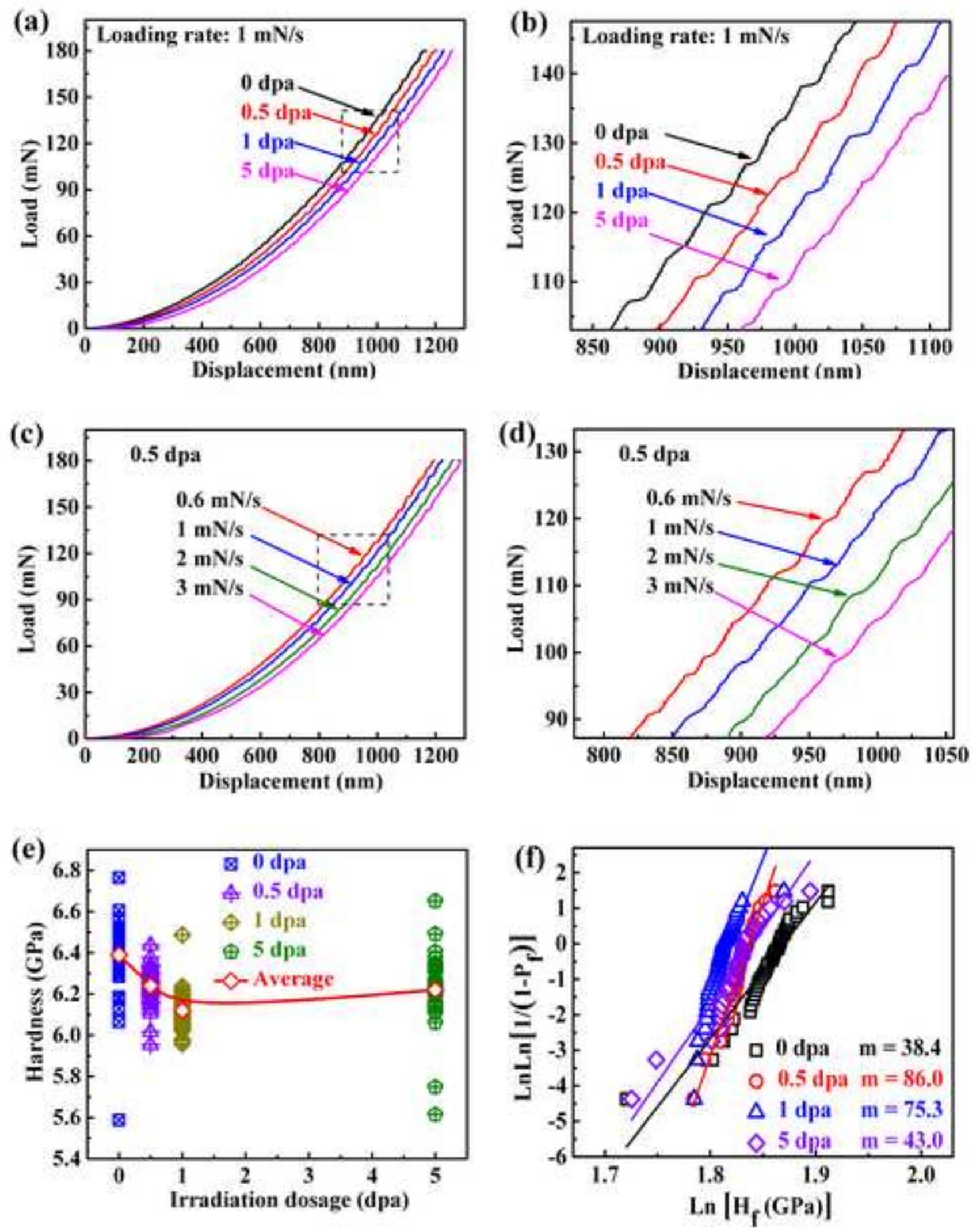




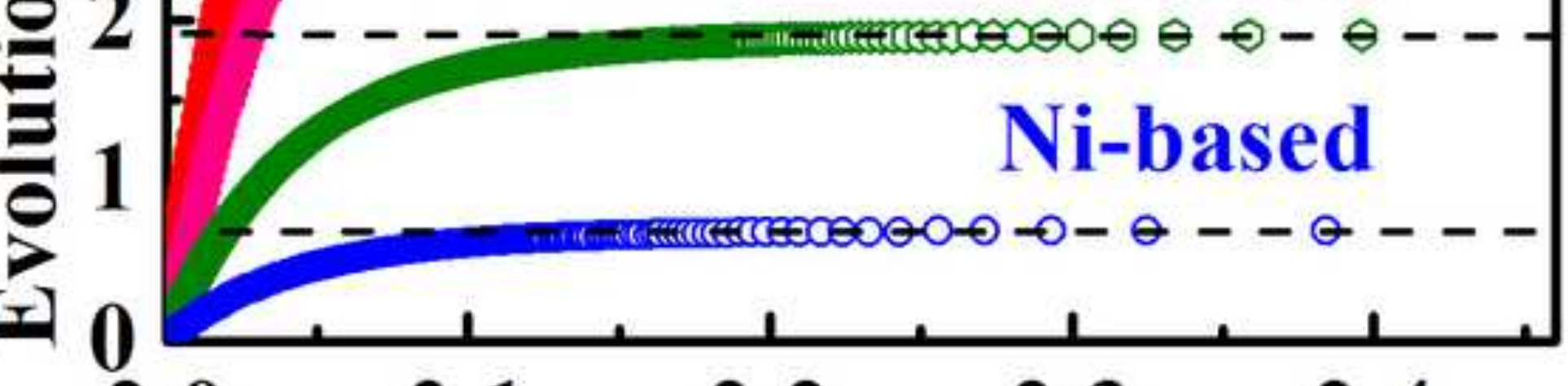

\section{Cu-based}

Zr-based Free-volume fraction (\%) 

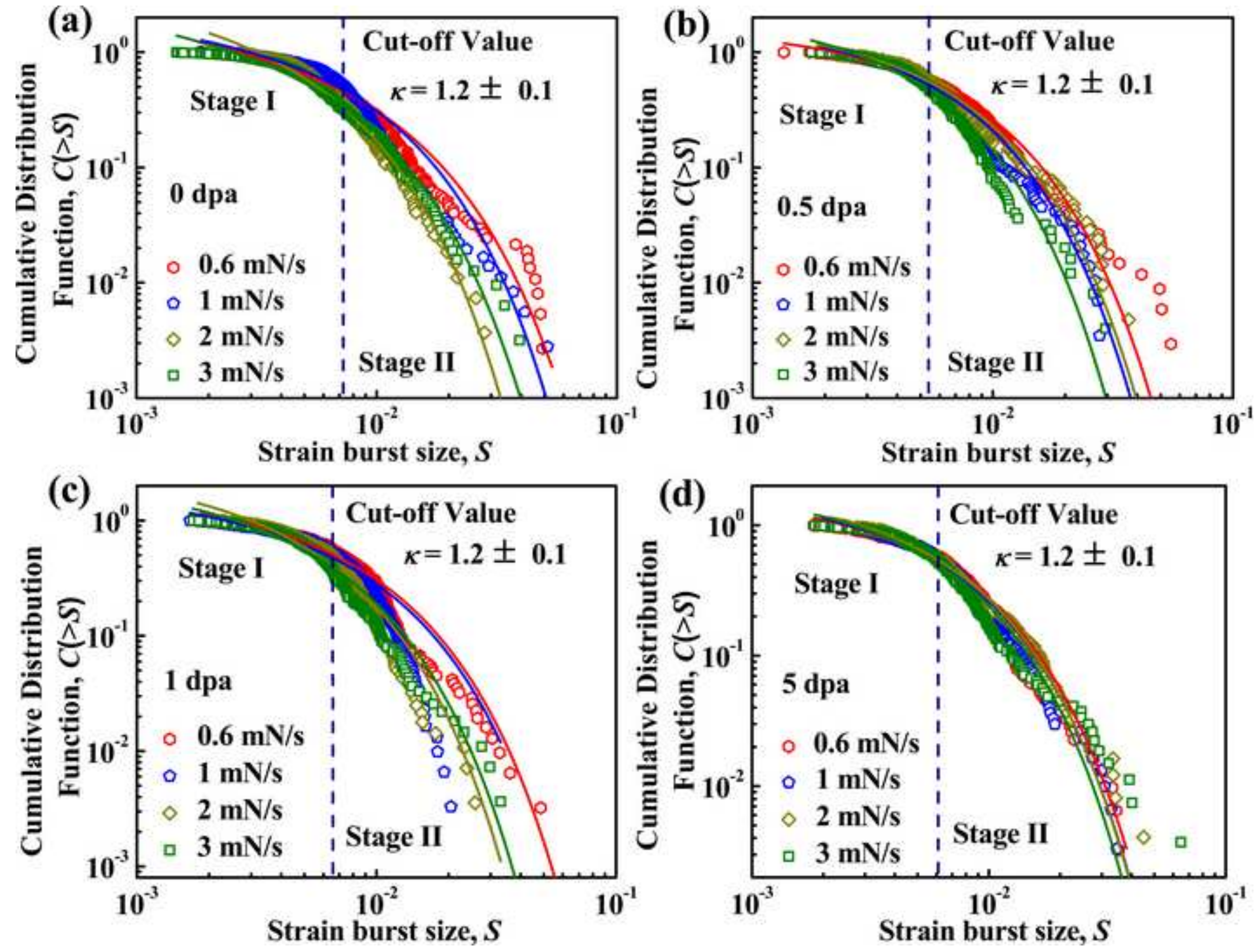


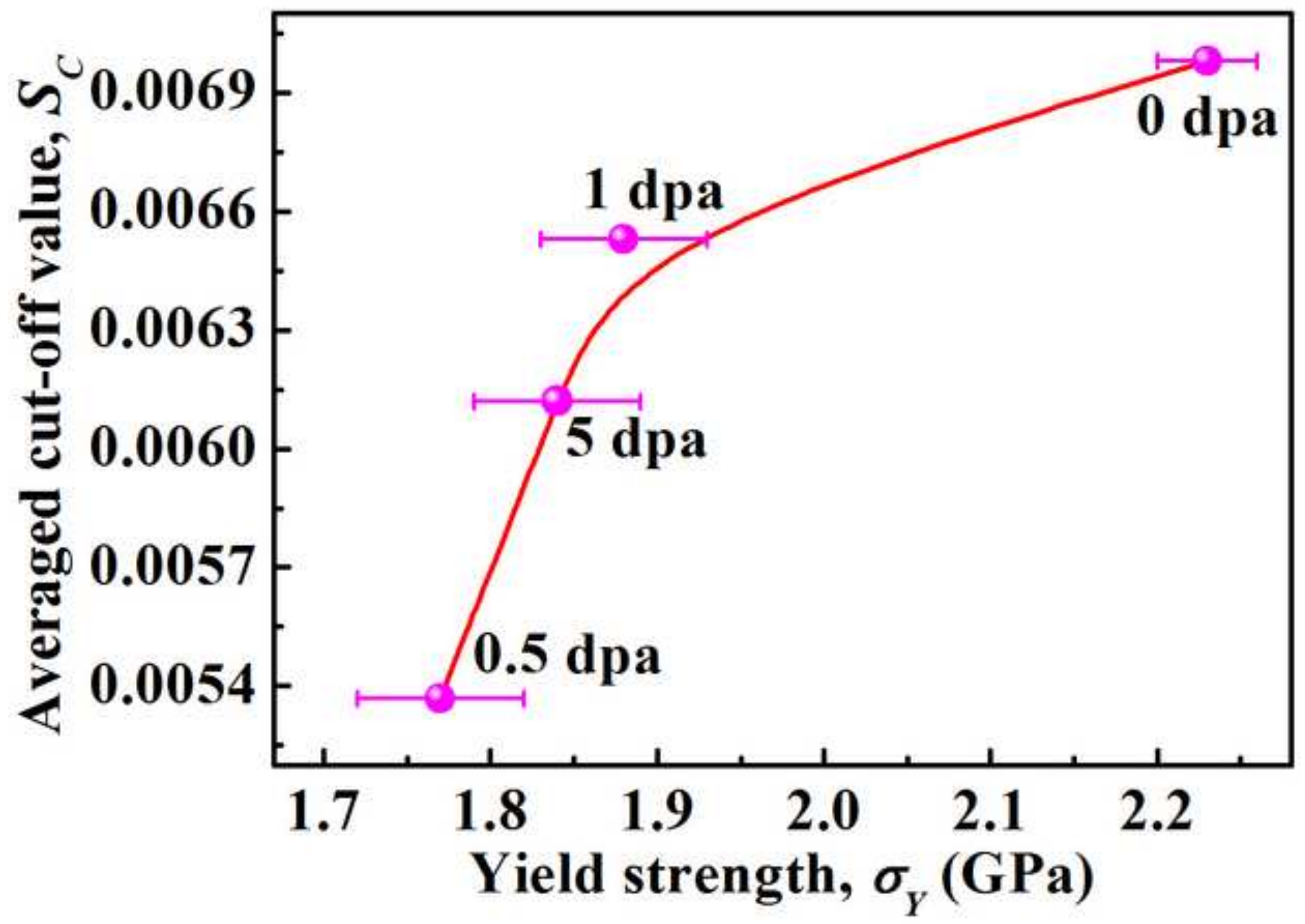




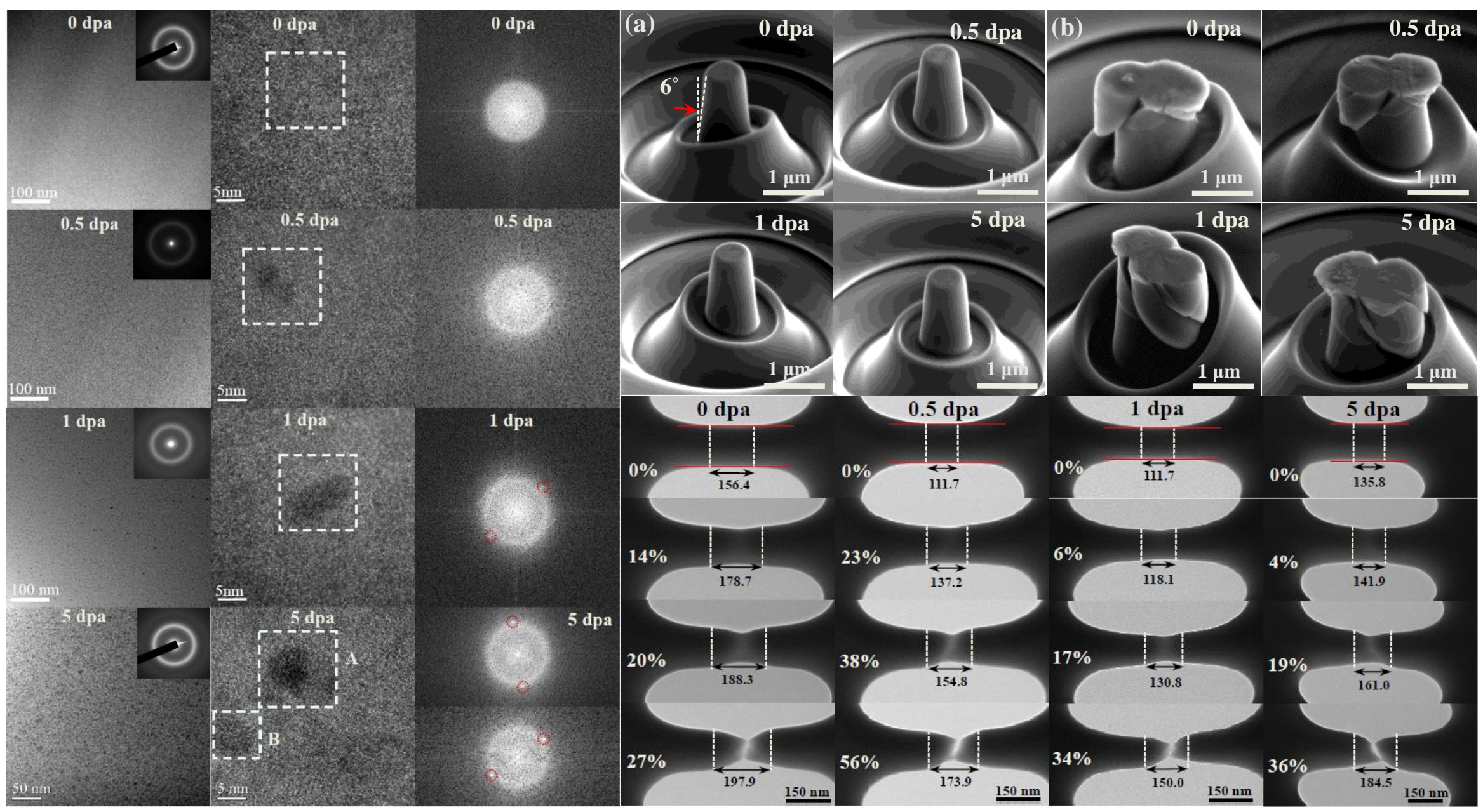

